REALA, nos 315-316, enero-agosto 2011, ISSN: 1699-7476

\title{
Desafíos de los entes locales: un nuevo modelo de gobierno con proyección exterior
}

\author{
María Remedios Zamora Roselló \\ Doctora en Derecho. Doctorado Europeo \\ Profesora Ayudante-Doctor de Derecho Administrativo Universidad de Málaga \\ remedios@uma.es \\ Recibido: 28 de mayo de 201 \\ Aceptado: 18 de julio de 2012
}

\begin{abstract}
Resumen
La Administración local está llamada a convertirse en un actor básico en la adopción de decisiones a todos los niveles institucionales. Las novedades que esta realidad presenta en el panorama administrativo permiten abordar el estudio de dos de los aspectos básicos de los futuros entes locales: su activa participación en la gobernanza multinivel y la perspectiva exterior de su actividad, a través de la cooperación y la colaboración con entes locales vecinos o de otros Estados. La diversidad de nuestras sociedades y la consecución de la cohesión económica, social y territorial a nivel comunitario determinan el sentido de los Entes locales y las funciones que deberán asumir.
\end{abstract}

Palabras clave

Agrupaciones supramunicipales, cohesión, cooperación descentralizada y transnacional.

\section{Challenges of local authorities: a new model of government with an exterior projection}

\section{Abstract}

The local authority is called to be a core actor in the decision-making at all institutional levels. These developments in the administrative context can approach the study of two basic aspects of future local authorities: their active participation in multi-level governance and the external perspective of its activities, through cooperation and collaboration with neighboring local governments or from other States. The diversity of our societies and the attainment of economic, social and territorial cohesion at EU level determine the meaning of local organizations and the roles they will assume.

Key words

Supra-local authorities, cohesion, decentralized and transnational cooperation. 


\section{INTRODUCCIÓN}

Elaborar un estudio sobre la administración local supone abordar el modelo más básico de administración, pero no por ello el más simple. Los entes locales representan el primer nivel de la Administración, el rostro más visible de todo un entramado organizativo cuya principal finalidad es atender a la sociedad y evolucionar en función de sus demandas. Como primer eslabón de esta cadena administrativa, y por tanto, imagen y representación última de toda la Administración de un Estado, los entes locales debieran recibir una atención especial y representar los principios básicos del actual modelo administrativo; sin embargo, la administración local continúa ocupando una posición no ya secundaria, sino por completo residual.

La Administración General del Estado y las Comunidades Autónomas disponen de una capacidad económica y de un conjunto de competencias que convierten al nivel local en un actor olvidado en el panorama administrativo de primer orden. La proyección de lo local en la ciudadanía tampoco es halagüeña, ya que los casos de corrupción asociados a los gobiernos locales han generado un clima de desconfianza que aún no ha sido superado; revalorizar lo local frente a las injerencias del resto de administraciones, el asociacionismo y el desarrollo de los principios de la gobernanza se configuran como los instrumentos claves para que los entes locales puedan asumir el estatus que le corresponde en la Administración'.

Frente a esta realidad la administración local debe responder superando sus propias limitaciones, sus límites de gobierno y territoriales. La participación activa de los entes locales en la toma de decisiones no sólo a nivel regional o estatal, sino también a nivel comunitario e internacional supone avanzar un paso más en los nuevos principios de la gobernanza. La satisfacción de las necesidades básicas de la población, la configuración de una administración realmente descentralizada, y la atención a las recientes demandas ambientales y tecnológicas dependerán en gran medida de la capacidad de actuación de la administración local. Los entes locales están llamados a ocupar una posición estratégica ante los últimos cambios sociales y políticos, para lo que deben recuperar la confianza del ciudadano y reclamar la relevancia que merece en el entramado institucional.

La Agenda de Barcelona, resultado de las recomendaciones y propuestas que se alcanzaron en la Cumbre Europea de Gobiernos Locales², toma como punto de partida la futura política de cohesión en Europa basada en tres pilares: cohesión económica, social y territorial. Los gobiernos locales han de jugar un papel esencial en esta línea política, ya que constituyen las instituciones más próximas al ciudadano y al territorio; en este contexto, las instituciones locales están llamadas a hacer frente a estas novedades desde una doble perspectiva, caracterizada por la transversalidad, la integración y la integralidad, integrando las dimensiones económica, social y territorial que configuran la cohesión.

Las directrices comunitarias requieren de un sistema de gobernanza multinivel que permita integrar de forma activa a los gobiernos locales en las instituciones comunitarias, con el fin de dotar de una mayor eficacia, eficiencia y legitimidad a las políticas comunitarias. Esta construcción teórica exige una aplicación práctica real que ofrezca resultados, y la premisa indispensable es fomentar la presencia de gobiernos locales con suficiente autonomía para hacer frente a estos desafíos, es decir, entes locales con capacidad económica suficiente para asumir estas competencias.

\section{UN NUEVO MODELO DE GOBIERNO}

\section{Los principios de la gobernanza en la Administración Local}

Cada modelo de gobierno se enfrenta a sus propias dificultades, mientras que en el ámbito de la Unión Europea el ciudadano aún percibe a las instituciones comunitarias como entes alejados de su realidad y problemática diaria, a otros niveles la corrupción de los poderes públicos ha creado una brecha difícil de salvar entre la ciudadanía y las instituciones. Los nuevos modelos de gobernanza tratan de retomar al ciudadano e implicarlo activamente en las decisiones políticas.

Las políticas locales tienen una repercusión directa en los ciudadanos y ostentan una importancia estratégica para establecer un vínculo de confianza entre el ciudadano y los órganos locales; la relación administración local-

1 Sobre la participación ciudadana, Sánchez Morón, M., “Reflexiones sobre la participación del ciudadano en las funciones administrativas en el sistema constitucional español", Revista Catalana de Dret Públic, núm. 37, 2008, pp. 223-245. En relación a relevancia de la implicación ciudadana a nivel local en el ámbito de la rendición de cuentas, Medina Guerrero, M., La promoción de la rendición de cuentas y la participación ciudadana en los procesos de descentralización, FIIAPP-Instituto Universitario de Desarrollo y Cooperación, Madrid, 2006 , pp. 9-11.

Colino, C., "Democracia, participación ciudadana y problemas de la gestión de los gobiernos locales en Europa: la equidad, la eficiencia y la capacidad”, VII Congreso Internacional del CLAD sobre la Reforma del Estado y de la Administración Pública, Lisboa, 8-11 de octubre de 2002.

2 La Cumbre Europea de Gobiernos Locales se celebró entre el 22 y el 24 de febrero de 2010 bajo el lema "Gobiernos locales en red para una nueva Europa". 
ciudadano es la clave para garantizar la participación ciudadana y avanzar un paso más allá hasta lograr la responsabilidad del ciudadano en el esquema de la democracia local3. Esta cercanía con el ciudadano también se ha traducido en una mayor exposición de los representantes locales; el ciudadano se siente defraudado ante las actuaciones de sus representantes locales, y esta situación provoca un mayor rechazo, lo que implica su alejamiento de las instituciones públicas; recuperar al ciudadano y responsabilizarlo ante la problemática local es tarea clave4.

Este contexto es común a todas las Administraciones, pero la realidad política, social y económica de cada Estado determina los aspectos claves del debate sobre la gobernanza; esta fórmula para el ejercicio del poder público trata de romper los límites tradicionales y enfocar la actuación de los gobernantes hacia las demandas de la sociedad, logrando la presencia real del ciudadano en la toma de decisiones ${ }^{5}$. Si trasladamos esta realidad al nivel local se confirma que los ciudadanos demandan políticas innovadoras y comprometidas, a la vez que se muestran ajenos al propio debate político y desconfían de la clase política en general y de las propias instituciones.

En el año 2006 el Comité de las Regiones consideraba que el elemento básico de la buena gobernanza pasa por la asunción de que las decisiones se toman mejor en el nivel más cercano a los ciudadanos. El Comité apuesta por el establecimiento de entes locales con competencias y que gocen de la suficiente credibilidad para desarrollar la gobernanza como modelo de la descentralización democrática, y garantizar de esta forma el respeto de los derechos de los ciudadanos y la satisfacción de sus necesidades.

El Libro Blanco sobre la Gobernanza Europea enumeraba los siguientes principios básicos: apertura, participación, responsabilidad, eficacia y coherencia ${ }^{6}$. Como señala el propio texto de la Comisión, estos principios son la base de la democracia y el Estado de Derecho en los Estados miembros, y pueden aplicarse a todos los niveles de gobierno: mundial, europeo, nacional, regional y local. El Libro Blanco propuso abrir el proceso de elaboración de las políticas comunitarias para implicar a un mayor número de personas y organizaciones en su formulación y aplicación, y alcanzar de esta forma un nivel más elevado de transparencia. Para alcanzar este objetivo, desde la

3 Castel Gayán, S., “La participación ciudadana en el ámbito local: experiencias”, publicado en el núm. 312 de esta Revista, pp. 9-37. De este mismo autor, “Descentralización política, participación ciudadana y renovación jurídica:¿Hacia una democracia participativa?”, Revista Catalana de Dret Públic, núm. 43, 2011, p. 282: "La cercanía de los asuntos públicos al ciudadano y el mejor conocimiento de sus necesidades por la Administración autonómica, fueron algunos de los argumentos que apoyaron el desarrollo del Estado autonómico. Sin embargo, esta realidad no ha supuesto una participación real y efectiva en los asuntos públicos, al margen del clásico derecho de representación política. Así, una vez consolidado el sistema político y territorial-sin perjuicio de aquellos debates que perfilan la agenda actual-, el modelo español se enfrenta a un nuevo reto: mejorar la calidad democrática del Estado autonómico a través de un proceso que fomente la democracia participativa en su funcionamiento".

4 En este sentido podemos citar el fenómeno de la corrupción administrativa y política vinculado a la urbanización masiva en España. A este respecto ha tenido la oportunidad de pronunciarse la Unión Europea en el Informe sobre el impacto de la urbanización extensiva en España en los derechos individuales de los ciudadanos europeos, el medio ambiente y la aplicación del Derecho comunitario, con fundamento en determinadas peticiones recibidas (2008/2248(INI)), Comisión de Peticiones, ponente: Margrete Auken; y en la Resolución del Parlamento Europeo, de 26 de marzo de 2009, sobre el impacto de la urbanización extensiva en España en los derechos individuales de los ciudadanos europeos, el medio ambiente y la aplicación del Derecho comunitario, con fundamento en determinadas peticiones recibidas (2008/2248(INI)).

En estos estudios las instituciones comunitarias han constatado que el sistema español de urbanización masiva no ha respetado los derechos de los propietarios y ha destruido el entorno natural en muchas zonas del litoral y el interior de España. Entre las conclusiones de estos documentos cabe destacar las apreciaciones que realiza sobre la responsabilidad de las Administraciones públicas "responsables de haber puesto en marcha un modelo de desarrollo insostenible, que ha tenido gravísimas consecuencias, por supuesto medioambientales y, además, sociales y económicas".

Sánchez Blanco, A., “Urbanismo, prácticas municipales y evaluación institucional del Estado Español: la Resolución del Parlamento Europeo sobre el impacto de la urbanización extensiva en España en los derechos individuales de los ciudadanos europeos, el medio ambiente y la aplicación del Derecho comunitario", publicado en el núm. 310 de esta Revista, pp. 9-37.

5 Natera Peral, A., "La gestión de redes de gobernanza: un reto para el Estado y la democracia”, Revista Administrație şi management public, núm. 3, 2004, p. 155, afirma: “La aparición de la gobernanza como tema "caliente” de análisis se ha derivado en gran medida del debate habido en las últimas décadas en torno a las transformaciones del Estado, y de la propia sociedad. De este modo, uno de los denominadores comunes en la perspectiva de la gobernanza radica en considerar que el Estado ha dejado de tener el monopolio sobre los conocimientos y sobre los recursos económicos e institucionales necesarios para gobernar, así como una tendencia a hablar de la influencia creciente de los actores no gubernamentales en tanto que cambio significativo con respecto al pasado reciente. En dichas transformaciones han confluido factores muy diversos”. Sánchez Blanco, A., Organización Intermunicipal, lustel, Madrid, 2006.

Sandri, G., "Le politiche strutturali comunitarie e le regioni: modelli di partecipazione subnazionale al decision-making europeo ", XXI Congresso della Società Italiana di Scienza Politica, Università di Catania, Facoltà di Scienze Politiche, 20-22 Septiembre, 2007.

6 Comisión de las Comunidades Europeas, Libro Blanco de la Gobernanza, COM(2001), 428 final, Bruselas, 25 de Julio de 2001 ; Comisión de las Comunidades Europeas, Comunicación al Consejo, al Parlamento Europeo y al Comité Económico y Social sobre Gobernanza y Desarrollo, $\operatorname{COM}(2003) 615$ final, Bruselas, 20 de Octubre de 2003; Comisión de las Comunidades Europeas, Comunicación al Consejo, al Parlamento Europeo y al Comité Económico y Social "La gobernanza en el consenso europeo sobre política de desarrollo. Hacia un enfoque armonizado en la Unión Europea”, $\operatorname{COM(2006)} 421$ final, Bruselas, 30 de agosto de 2006; Comité de las Regiones, Dictamen del Comité "La gobernanza en el consenso europeo sobre la política de desarrollo", DO C 197 de 24 de agosto de 2007, pág. 52-56; Navarro Gómez, C., "Gobernanza en el ámbito local”, VII Congreso Internacional del Centro Latinoamericano de Administración para el Desarrollo sobre la Reforma del Estado y de la Administración Pública, Lisboa (Portugal), 8-11 octubre 2002. 
Comisión Europea se realizaba un llamamiento más allá de las instituciones comunitarias, que incluía a las administraciones estatales, regionales y municipales, y a la sociedad civil.

La construcción de un régimen democrático basado en un modelo de administración descentralizada exige como premisa básica el fortalecimiento de las entidades locales. Por tanto, las iniciativas de la Unión se centran en la significación de la Administración Local como nexo de unión entre el ciudadano y las instituciones públicas en general. El Libro Blanco trataba de garantizar la conexión entre el ciudadano y las instituciones públicas, ya que el riesgo en la ruptura de este vínculo es la deslegitimación de las instituciones comunitarias. La participación de los entes locales en la elaboración de las disposiciones comunitarias es una garantía de efectividad para las medidas adoptadas; la Unión Europea opta por la apertura en todas las etapas del proceso de decisión como medio para garantizar una mayor transparencia. Dotar a los municipios, junto a los entes regionales y a la sociedad civil, de una mayor presencia en las políticas comunitarias permite involucrar a sectores que permanecían ajenos al procedimiento de decisión comunitario?.

En marzo de 2010 la Comisión Europea presentó su Comunicación “Europa 2020.Una estrategia para un creci-

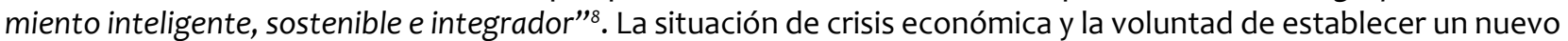
modelo basado en un sistema económico inteligente, sostenible e integrador, constituyen el contexto en el que se elabora este documento ${ }^{9}$. Con la Estrategia Europa 2020 también se sustituye la Estrategia de Lisboa, adoptada en el año 2000, para dar cabida a las demandas actuales en el entorno comunitario; en esta línea la Comisión propone para la UE cinco objetivos cuantificables para 2020 que marcarán la pauta del proceso y se traducirán en objetivos nacionales: el empleo, la investigación y la innovación, el cambio climático y la energía, la educación y la lucha contra la pobreza.

Para conseguir resultados la Estrategia apuesta por una gobernanza fortalecida, basada en un planteamiento temático y en los informes por país. El planteamiento temático toma como referencia los cinco objetivos prioritarios citados ${ }^{10}$, refleja la interdependencia de las economías de los Estados miembros y aspira a favorecer la selección de iniciativas concretas que impulsen la Estrategia y la consecución de sus fines.

Los informes por país se centran en las estrategias que procuren la salida de la crisis, restaurar la estabilidad macroeconómica, detectar los problemas nacionales y que las economías nacionales se asienten sobre un crecimiento y unas finanzas públicas sostenibles. La finalidad última es la planificación integral de las medidas políticas y su ejecución, abarcando desde la política fiscal hasta los aspectos macroeconómicos relacionados con el crecimiento y la competitividad.

El estrecho control que se realiza en la evolución y puesta en práctica de la Estrategia se traduce en dos niveles: en el nivel del planteamiento temático se adoptarán recomendaciones relativas al empleo y recomendaciones por país y materias; mientras que a nivel de la vigilancia por país se elaborarán dictámenes sobre los programas de estabilidad y convergencia de conformidad con el Reglamento 1466/97 del Consejo, acompañadas por recomendaciones en el marco de las Grandes Orientaciones de Política Económica. Las recomendaciones se caracterizan por su concreción y por su calendario, el incumplimiento por parte de los Estados miembros se puede traducir en una advertencia política, consecuencia de la adopción de políticas contrarias a la recomendación o de no responder adecuadamente a las indicaciones comunitarias.

La Estrategia parte de la premisa de cooperar para alcanzar los objetivos, afirmación que se traduce en la indispensable participación de las autoridades nacionales, regionales y locales, de los interlocutores sociales y de la sociedad civil. La estrecha colaboración y el diálogo continuo entre varios niveles de Gobierno favorece el acercamiento de las prioridades de la Unión Europea a los ciudadanos, completado con iniciativas como el intercambio de buenas prácticas, la evaluación comparativa y el establecimiento de redes.

7 Börzel, T., "European Governance: Negotiation and Competition in the Shadow of Hierarchy", JCMS: Journal of Commoon Market Studies, vol. 48, núm. 2, marzo 2010, pp. 191-219; Calame, P., La démocratie en miettes. Pour une révolution de la gouvernance, Descartes \& Cie, París, 2003.

8 Comisión de las Comunidades Europeas, Comunicación Europa 2020. Una estrategia para un crecimiento inteligente, sostenible e integrador, $\operatorname{COM}(2010)$ 2020, Bruselas, 3 de marzo de 2010.

9 García-Santesmases Fernández, A., Documentación social, núm. 157, 2010, pp. 225-242; Erixon, F., “The Europe 2020 strategy: time for Europe to think again”, European View, vol. 9, núm. 1, junio de 2010, pp. 29-37; Lannoo, K., “Europe 2020 and the Financial System: Smaller is beautiful”, Centre for European Policies Studies. Policy Brief, núm. 211, julio 2010, pp. 1-6, disponible en: http://www.ceps.eu . Mariscal, N., Más allá de Lisboa: Horizontes europeos, Editorial Tecnos, 2010.

10 En el Anexo I se concretan estos objetivos principales: “-La tasa de empleo de la población de entre 20 y 64 años debería pasar del actual $69 \%$ a, como mínimo, el 75\%; -Alcanzar el objetivo de invertir el3\% del PIB en I+D, en particular mejorando las condiciones para la inversión en I+D por parte del sector privado y desarrollando un nuevo indicador que haga un seguimiento de la innovación; -Reducir las emisiones de gases de efecto invernadero en un $20 \%$ en comparación con los niveles de 1990, incrementar el porcentaje de las energías renovables en nuestro consumo final de energía al $20 \%$ y aumentar un $20 \%$ la eficacia en el uso de la energía; -Reducir el porcentaje de abandono escolar al 10\% desde el actual $15 \%$ e incrementar el porcentaje de personas de entre 30 y 34 años con estudios superiores completos del 31\% a, como mínimo, un 40\%; -Reducir el número de europeos que viven por debajo del umbral nacional de pobreza en un $25 \%$, liberando de la pobreza a 20 millones de personas". 
A nivel nacional, las principales pautas sobre las que se puede calibrar la evolución de los entes locales se definen a partir de tres elementos: el reconocimiento de la autonomía local, la relación entre entes locales y ciudadanos y la coordinación con las administraciones autonómicas, como segundo nivel territorial en nuestro Estado. Como ha señalado nuestro Tribunal Constitucional en su Sentencia 240/2006 de 20 julio, fundamento jurídico segundo: "la autonomía local, tal y como se reconoce en los arts. 137 y 140 CE, goza de garantía institucional; lo cual supone el derecho de la comunidad local a participar, a través de sus órganos propios de gobierno y administración, en cuantos asuntos le atañen, graduándose la intensidad de esa participación en función de la relación existente entre los intereses locales y supra locales en dichos asuntos o materias (SSTC 84/1982, de 23 de diciembre; 170/1989, de 19 de octubre). Esta autonomía no tendría sentido alguno si los órganos representativos de la comunidad local no tuvieran las potestades necesarias para su ejercicio (SSTC 84/1982, de 23 de diciembre; 170/1989, de 19 de octubre; 148/1991, de 4 de julio; 46/1992, de 2 de abril). De modo que el reconocimiento de esas potestades es el con-tenido mínimo (en función de los intereses que debe tutelar) de la garantía institucional de la autonomía local, que como concepto jurídico indeterminado debe concretarse en tiempo y lugar"'1.

La elaboración de la política comunitaria desde el ciudadano implica la participación directa de las autoridades locales en las propuestas que se trasladen a las instituciones comunitarias. El desarrollo de la autonomía local, a la vista de este modelo de legitimación democrática de la Unión Europea, exige de la proyección hacia Europa de los entes locales. La realidad es que aún existen temas pendientes en el desarrollo de la autonomía local, entre los que destaca la financiación ${ }^{12}$, y que condicionan la capacidad de actuación de los entes locales y el desarrollo de la propia autonomía local.

Desde el año 2003 también se ha avanzado en la elaboración de un esquema participativo, en el que los ciudadanos puedan formar parte de la gestión municipal. Entre las modificaciones introducidas en la Ley de Bases de Régimen Local por la Ley 57/2003 se encuentra la obligación de los municipios de gran población de crear un Consejo Social de la Ciudad, integrado por representantes de las organizaciones económicas, sociales, profesionales y de vecinos más representativas. Las funciones de este Consejo serían la emisión de informes, estudios y propuestas en materia de desarrollo económico local, planificación estratégica de la ciudad y grandes proyectos urbanos ${ }^{13}$.

La creación de los distritos también se configura como un paso más en el impulso de la participación ciudadana. La base para este modelo de gestión se encuentra en el artículo 24 LBRL, que faculta a los municipios a establecer órganos territoriales de gestión desconcentrada, con la organización, funciones y competencias que les confieran los Ayuntamientos en función de sus propias características. En esta línea, el Reglamento ya otorgó competencia a los Ayuntamientos para crear las Juntas Municipales de Distrito, con el fin de mejorar la gestión y favorecer la participación ciudadana ${ }^{14}$.

En la reforma de 2003 se introdujo una nueva referencia a esta gestión desconcentrada, obligando a los municipios de gran población a crear los distritos, como divisiones territoriales propias dotadas de órganos de gestión

11 El fundamento jurídico segundo de la citada STC, también establece: “Ahora bien, la autonomía local es un concepto jurídico de configuración legal que puede construirse respondiendo opciones muy diversas, todas ellas admisibles siempre que respeten la garantía institucional que deriva de la Constitución (STC 170/1989, de 19 de octubre). De ahí que la garantía institucional de la autonomía municipal que nuestra Constitución establece supone una doble remisión. Por una parte, a unos rasgos con capacidad identificadora de lo que es un municipio y de lo que su autonomía supone en la conciencia social y en el momento actual, extremos que no pueden quedar al arbitrio del legislador ordinario. Por otra, a la configuración normativa que dicho legislador ordinario haga de la estructura, funcionamiento y competencias del municipio y de su corporación representativa, pero sin que el legislador ordinario pueda efectuar esa configuración sin limitación. Como el Tribunal Constitucional tiene declarado, más allá de un contenido mínimo de la autonomía el legislador ordinario puede aumentar el ámbito de la autonomía local (STC 148/1991, de 4 de julio), pero no es menos evidente que la configuración legal de ésta, a través de una decantación histórica que el constituyente tuvo presente al establecer la correspondiente garantía en los arts. 137 y 140, ha de ser también tenida en cuenta (STC 37/1981, de 16 de noviembre, F. 1). Esto es, la determinación de los intereses que definen el ámbito de la autonomía local ha de venir establecida por la Ley, pero no arbitrariamente, sino con referencia al orden concreto que integra el régimen jurídico de la Administración local”.

12 En este sentido se manifiestaba el Sr. Tejada Gallegos, Teniente de Alcalde del Ayuntamiento de Córdoba y Miembro de la Comisión de Haciendas Locales de la FEMP, en la Mesa de debate titulada "Marco jurídico y financiero para un modelo territorial cooperativo", publicado por la Federación Española de Municipios y Provincias, en El municipalismo en un Estado cooperativo, 2009, pp. 126 y 127: “Los Ayuntamientos, desde luego, somos la institución más cercana a la ciudadanía y a la que se dirigen casi todas las demandas, demandas de todo tipo: vivienda, servicios sociales, trabajo, etcétera. Lo cierto es que la suficiencia financiera, de la que habla el artículo 142 de la Constitución, no se ha producido hasta ahora. Los servicios impropios existen, se produce una realidad en la que estamos asumiendo competencias impropias sin financiación adecuada. Por ello, pienso que hay que modificar la Ley de Bases de Régimen Local, de manera que contemple, en toda su amplitud, el principio de subsidiariedad, para que los ámbitos competenciales propios de la entidad estatal o la autonómica se den cuando desde la entidad local no se puedan suministrar. Habría que ir a un reparto de las competencias entre todos los niveles de la Administración, en el que optimicemos las funciones de cada una. Probablemente haya competencias y servicios de competencia compartida. No se trata de luchar por la exclusividad de las competencias, sino por coordinarse para prestar servicios de una manera más eficiente".

13 El art. 131.1 de la Ley 7/1985, de 2 de abril, Reguladora de las Bases del Régimen Local (LBRL), regula este Consejo, su composición y funciones. El Pleno del Ayuntamiento es competente para la ordenación de este órgano, en virtud de lo previsto en el art. 123.1.C) LBRL.

14 Art. 128 Real Decreto 2568/1986, de 28 de noviembre, por el que se aprueba el Reglamento de Organización y Funcionamiento y Régimen Jurídico de las Corporaciones Locales. 
desconcentrada, para impulsar y desarrollar la participación ciudadana en la gestión de los asuntos municipales y su mejora, sin perjuicio de la unidad de gobierno y gestión del municipio. El Alcalde ostenta la competencia para nombrar y cesar al concejal que presidirá cada distrito, si bien corresponde al Pleno de la Corporación la creación y regulación de los distritos mediante normas de carácter orgánico ${ }^{15}$.

La Comisión especial de Sugerencias y Reclamaciones también se configura como un órgano esencial en la relación del ciudadano con la administración municipal. Este órgano, de creación obligatoria en los municipios de gran población y facultativa en el resto de municipios, tiene como misión la defensa de los derechos de los vecinos ante la Administración municipal; a este fin la Comisión podrá supervisar la actividad de la Administración municipal, y deberá dar cuenta al Pleno anualmente de las quejas presentadas y de las deficiencias observadas en el funcionamiento de los servicios municipales, especificando las sugerencias o recomendaciones no admitidas por la Administración municipal, además de realizar informes extraordinarios cuando la gravedad o la urgencia de los hechos lo aconsejen. Representantes de todos los grupos que integren el Pleno forman esta Comisión, de forma proporcional al número de miembros que tengan en el mismo ${ }^{16}$.

En lo que respecta a las relaciones entre las Comunidades Autónomas y los Entes Locales, podemos señalar la creación por parte de la Ley de Autonomía Local de Andalucía del Consejo Andaluz de Gobiernos Locales, una demanda de la Federación Andaluza de Municipios y Provincias. Este Consejo se configura como el órgano de representación de los municipios y las provincias ante las instituciones de la Junta de Andalucía y su objetivo es garantizar el respeto a las competencias locales. Con el fin de alcanzar este fin, el Consejo Andaluz de Gobiernos Locales es competente para conocer con carácter previo los anteproyectos de Leyes, planes y proyectos de disposiciones generales elaborados por la Comunidad Autónoma que afecten a las competencias locales propias, e informar sobre su impacto ${ }^{17}$.

Este desarrollo paulatino del ámbito local, lastrado en ocasiones por las reticencias del resto de administraciones (estatal y autonómica), responde a las demandas de las instituciones comunitarias y de los foros internacionales, pero también a las propias demandas de la ciudadanía. El fortalecimiento del ciudadano en el marco de la gestión pública pasa por los entes locales; las iniciativas políticas son una respuesta a las demandas de la sociedad y como tales deben configurarse a partir de la participación de la población local, núcleo básico para el desarrollo de las iniciativas comunitarias, estatales y autonómicas.

\section{COHESIÓN SOCIAL, MIGRACIÓN Y GOBERNANZA}

En el I Foro de gobiernos locales de la Unión Europea, América Latina y el Caribe se tomó como referencia un concepto de cohesión social que se refiere "a un conjunto de elementos que permiten a los ciudadanos compartir un sentimiento de pertenencia e inclusión, reconocerse mutuamente en la diversidad y participar de manera activa en las políticas públicas, con un sentido de responsabilidad colectiva". En la Declaración Final del Foro se destaca la necesidad de "potenciar una dimensión integral del concepto de cohesión social, que debe vincularse a las distintas políticas públicas locales en ámbitos como el desarrollo económico local, la inclusión social, la construcción de ciudadanía, la articulación del territorio y la seguridad ecológica”18.

El concepto cohesión social coincide con los principios de buena gobernanza trazados por la Unión Europea pero añade un componente más que podríamos definir como el elemento de pertenencia local, el sentimiento de colectivo de todos los integrantes. Este plus que se añade a los tradicionales elementos de la gobernanza también fortalece el poder local; la identificación del ciudadano con la administración local y la capacidad de ésta última de integrar en su seno a toda la población es el desafío clave de la buena gobernanza. Este sentimiento de pertenencia e identificación adquiere una especial relevancia ante el desafío que supone la recepción de personas de distintos orígenes, gracias a fenómenos como la inmigración, que sitúa a los entes locales en primera línea de acción para hacer frente a esta nueva situación.

Las sociedades multiculturales también demandan nuevas atenciones por parte de los gobiernos locales. Cada localidad debe tomar conciencia de su propia diversidad, atendiendo a singularidades como las distintas lenguas, razas o religiones que conviven en su territorio. La integración de estas diferencias es fundamental para lograr que la diversidad se traduzca en enriquecimiento y no en confrontación, a través del diálogo y el respeto, y sobre la base de los valores básicos del sistema democrático; cada gobierno local está llamado a dedicar parte

15 Arts. 123.1.c), 124.4.e) y 128 LBRL.

16 Arts. 20.1.d) y 132 LBRL.

17 Art. 57 de la Ley 5/2010, de 11 de junio, de Autonomía Local de Andalucía.

18 I Foro de Gobiernos Locales de la Unión Europea, América Latina y el Caribe “Cohesión Social y Cooperación Descentralizada”, París, 29-30 de noviembre de 2007, Declaración Final, párrafo 2. 
de su atención a este desafío' ${ }^{19}$. Esta realidad también se encuentra estrechamente relacionada con la proyección exterior de los entes locales. El conocimiento mutuo a través de estas relaciones internacionales tiene si cabe más sentido, cuando nos encontramos con una importante presencia de habitantes de distintos orígenes en todas las localidades.

La presencia de la diversidad es un nuevo contexto que necesita de políticas públicas propias. En el ámbito local adquieren una gran relevancia las políticas sociales porque sólo este nivel de la Administración se encuentra capacitado para atender las demandas diarias del ciudadano, ya que es el único que conoce directamente las necesidades de su población y la mejor forma de subsanarlas. Un aspecto vinculado a estas nuevas necesidades sería la dotación de infraestructuras que permitieran la asistencia a los distintos cultos religiosos o la reunión de grupos que aspiren a mantener sus tradiciones culturales o lingüísticas.

La pluralidad debe erigirse como valor en las políticas locales, ya que la actitud contraria supondría socavar la armonía de una población. Si las políticas locales se muestran reacias, o incluso contrarias, a la elaboración de experiencias públicas que atiendan a la diversidad se convierten en un riego para la configuración de las sociedades multiculturales; desde los entes locales se puede minar con gran eficacia la armonía social de un territorio. Por ello, la elaboración de políticas locales coherentes con las necesidades sociales constituye una prioridad para la construcción de un modelo que permita alcanzar el objetivo último de cualquier ente local: el servicio al ciudadano y la atención a sus demandas. Cada ente local, atendiendo a los condicionantes sociales, culturales y económicos, tendrá que elaborar una política propia basada en el ciudadano, con el amplio espectro de realidades que ello significa. Los entes locales condicionan en gran medida la vida diaria de cualquier ciudadano, su espacio de trabajo, su ocio, su lugar de relación, la participación ciudadana, en definitiva la forma de vida de una población.

Un ejemplo de la voluntad de algunos municipios por adaptarse a las nuevas demandas sociales es la Carta municipal de Barcelona, que define la diversidad como un valor para la ciudad ${ }^{20}$. En este texto se adoptaron disposiciones cuya finalidad última es la participación ciudadana en el gobierno de la ciudad y en la gestión de sus servicios ${ }^{21}$; esta voluntad de acercar al ciudadano e implicarlo directamente en la vida política, social y cultural de su localidad incluye unas referencias propias para la población de origen extranjero. Como ciudadanos de Barcelona, empadronados en esta ciudad, también están llamados a participar en referéndums y otros procedimientos consultivos que promueva el Ayuntamiento ${ }^{22}$. El municipio actúa como eje vertebrador de la integración de los extranjeros en España, como primer eslabón administrativo en el que participar de forma directa y en el que implicarse para defender sus intereses.

La integración europea es un fenómeno que se sigue desarrollando de forma paralela a esta integración de población extranjera en nuestras sociedades. Los entes locales participan en redes internacionales de cooperación, a la vez que el componente internacional existe dentro de cada territorio local. El éxito de los municipios depende en gran medida de la diversidad, de su capacidad para actuar como punto de encuentro de personas con distintos orígenes, cultura, lengua, religión, raza, conocimientos... La prestación de los servicios públicos en el ámbito local debe reorientarse hacia el esquema de una sociedad diversa, que exige una cambio hacia una estruc-

19 Clark, G., “Ciudades abiertas, gobernanza y cohesión” en Pascual Esteve, J. y Pascual Guiteras, J. (coords.), Cohesión Social y Gobernanza democrática: Para unas regiones y ciudades más inclusivas, Junta de Andalucía, Consejería de Gobernación, pp. 31-49.

20 Ley 22/1998, de 30 de diciembre, de la Carta Municipal de Barcelona (BOE núm. 28, de 2 de febrero de 1999). Esta disposición ha sufrido varias modificaciones desde su aprobación, las últimas novedades fueron introducidas por la Ley $7 / 2010$, de 21 de abril, y su finalidad fue incorporar la regulación del Consejo Económico y Social de Barcelona como órgano municipal de naturaleza consultiva y carácter general.

21 El art. 34 de la Carta hace referencia la posibilidad de la gestión cívica como instrumento para la integración ciudadana en los servicios de la ciudad. En este precepto se afirma: "Las entidades, organizaciones y asociaciones ciudadanas sin ánimo de lucro pueden ejercer competencias municipales o participar en nombre del Ayuntamiento, en la gestión de servicios o equipamientos cuya titularidad corresponde a otras Administraciones Públicas. La gestión cívica de competencias municipales puede utilizarse para las actividades y servicios susceptibles de gestión indirecta, tiene siempre carácter voluntario y no lucrativo y se adjudica mediante concurso público cuando existan varias entidades u organizaciones con idénticas o parecidas características".

Como ha señalado Fabeiro Mosquera, A., “La Carta municipal de Barcelona: Notas sobre sus especialidades”, RDUNED: Revista de Derecho de la UNED, núm. 1, 2006, p. 51: "La gestión cívica consistente en el ejercicio de social como en lo relativo al acceso a los servicios públicos esenciales. Pero sobretodo, el municipio es el lugar de integración cívica y política”. De este mismo autor, La Carta Municipal de Barcelona. Diez estudios, Marcial Pons, 2007. competencias municipales o participar en nombre del Ayuntamiento en la gestión de servicios titularidad de otras administraciones públicas; tiene carácter voluntario y no lucrativo, sólo válida para la gestión de servicios o actividades susceptibles de gestión indirecta. Esta fórmula permite involucrar al colectivo de organizaciones y asociaciones ciudadanas o vecinales en políticas de solidaridad, integración inmigrantes, atención a personas con discapacidad, dependencia, etc."

Font i Llovet, T., “La Carta Municipal de Barcelona en la reforma del régimen local”, Punt de vista, n 7, Fundación Pi y Suyer, 2000, p. 18, donde afirma: "el ámbito municipal es el punto de referencia primario para los inmigrantes, tanto por lo que se refiere a su incorporación a la vida ciudadana, cultural y social como en lo relativo al acceso a los servicios públicos esenciales. Pero sobretodo, el municipio es el lugar de integración cívica y política”. De este mismo autor, La Carta Municipal de Barcelona. Diez estudios, Marcial Pons, 2007.

22 Art. 10.5 de la Carta Municipal de Barcelona. 
tura menos homogénea y que pueda atender a las distintas necesidades de los ciudadanos; actuaciones que se encuentran estrechamente vinculadas con los planes para la regeneración y recuperación de los espacios públicos, y la elaboración de políticas de inclusión social.

\section{EL NUEVO PROTAGONISMO DE LA ADMINISTRACIÓN LOCAL}

El Comité de las Regiones en el Libro Blanco de la Gobernanza multinivel define este modelo como "la acción coordinada de la Unión, los Estados miembros y los entes regionales y locales, basada en la asociación y destinada a elaborar y aplicar las políticas de la Unión Europea. La misma induce la responsabilidad compartida de los diversos niveles de poder en cuestión y se basa en todas las fuentes de legitimidad democrática y en la representatividad de los diversos agentes implicados" ${ }^{23}$.

Esta definición nos ofrece varios puntos sobre los que el Comité ha decidido centrar su atención: legitimación democrática e institucional, participación ciudadana, coordinación y coherencia de las políticas comunitarias, novedades en el proceso de decisión de las políticas comunitarias.

a) Legitimación democrática e institucional: Las instituciones comunitarias aspiran a llegar al ciudadano por la vía de la democracia regional y local; en el Libro Blanco de la Gobernanza la Comisión consideraba que la mayor participación de las autoridades regionales y locales en las políticas de la Unión y de algunos Estados miembros es un ejemplo del mayor compromiso ciudadano y su mayor implicación en los procesos de la democracia local. Sin perjuicio de las dificultades que ofrece el propio sistema comunitario para la participación de las administraciones regionales y locales, el Libro Blanco de la Gobernanza se detenía en las reticencias estatales a la participación de los niveles regionales y locales en la política comunitaria.

El Comité de las Regiones ha incidido en este principio en el Dictamen elaborado a propósito del seguimiento sobre la aplicación del Libro Blanco. En este sentido el Comité ha apostado por la creación de una "Carta de la Unión Europea de la gobernanza multinivel” que tendrá como fin una mayor participación de los entes locales y regionales en el ejercicio de la democracia europea ${ }^{24}$.

b) Participación ciudadana: La población no es simple receptora de las iniciativas locales, es actor principal de las mismas y, en consecuencia, responsable de su efectividad. En este ámbito, la legitimidad de las instituciones públicas es esencial en el establecimiento de una relación de confianza con los ciudadanos. Como se ha señalado en el II Foro de Gobiernos Locales de la Unión Europea, América Latina y el Caribe la participación ciudadana y la democracia local son elementos claves de la cohesión social, de la democracia y de la gobernabilidad ${ }^{25}$.

La implicación de los interlocutores sociales y de la sociedad civil es uno de los objetivos principales de la futura UE. Los ciudadanos, las empresas y sus organizaciones representativas tienen que conocer de primera mano cuál es el sentido de las reformas, cómo influirán en nuestra calidad de vida y en nuestros modelos sociales y cuál debe ser la contribución de la sociedad civil y los interlocutores sociales. La Estrategia Europa 2020 establece este objetivo de comunicación como un instrumento clave para alcanzar el éxito de las iniciativas que se propongan ${ }^{26}$. Los gobiernos locales están llamados a jugar un papel fundamental en este ámbito, puesto que deben crear el espacio para que se produzca la participación ciudadana, las redes sociales de cooperación que participen de este nuevo modelo de gobernanza.

23 Comité de las Regiones, Libro Blanco del Comité de las Regiones sobre la Gobernanza Multinivel, $80^{\circ}$ Pleno, 17 y 18 de junio de 2009 , DOUE C 211, de 4 de septiembre de 2009, p. 1. Sobrino Heredia, J., "El principio de subsidiariedad y la participación de los entes locales y regionales en la Unión Europea”, Noticias de la Unión Europea, núm. 145, 1997, pp. 85-100; Marsal, M., “Los poderes locales ante el Tratado de Niza y la perspectiva de ampliación de la Unión Europea”, Anuario del Gobierno Local. Configuración Jurídica de la Autonomía Local. Municipio y transformaciones sociales. Urbanismo e Inmigración, Instituto de Derecho Público, Barcelona, 2001, pp. 245 270; Morata, F., "Gobernanza multinivel en la Unión Europea", VII Congreso Internacional del Centro Latinoamericano de Administración para el Desarrollo sobre la Reforma del Estado y de la Administración Pública, Lisboa (Portugal), 8-11 Octubre 2002. De este mismo autor, Gobernanza multinivel en la Unión Europea, Tirant Lo Blanch, 2004; Ordóñez Solís, D., “Los entes regionales y locales en la Unión Europea: La experiencia española”, Actualidad Administrativa, núm. 44, 1999, pp. 1237-1271; Vara Arribas, G., “Gobernanza multinivel en la Unión Europea y las regiones, con o sin una Constitución”, Revista Aragonesa de Administración Pública, núm. 29, 2006, pp. 309-332.

24 Dictamen del Comité de las Regiones, "Desarrollar una cultura europea de la gobernanza multinivel: El seguimiento del Libro Blanco del Comité de las Regiones", DOUE C 113, de 18 de abril de 2012.

25 II Foro de Gobiernos Locales de la Unión Europea, América Latina y el Caribe, “Innovando desde lo local”, Vitoria, 5-7 marzo de 2010. En este Foro se adoptó la denominada “Declaración de Vitoria”, en la que se expusieron las conclusiones alcanzadas tras el debate, el texto completo de este documento se puede consultar en http://www.femp.es

En relación a la importancia de la gobernabilidad y la participación ciudadanas, Blanco Velasco, M., "Gobernabilidad y participación ciudadana. Sociedad civil y gobierno panista", Gobernanza y gobernabilidad democráticas en México, Programa MOST, Documentos de debate, núm. 60, 2002, pp. 27-39.

26 Estrategia Europa 2020, citada en nota al pie núm. 7, pp. 31 y 32. 
Las últimas reformas estatutarias han tenido presente los elementos de la democracia participativa, abogando por la implicación del ciudadano y de las organizaciones sociales ${ }^{27}$. Esta tendencia supone el reconocimiento de la figura del ciudadano como corresponsable en la elaboración de las políticas públicas, ya que participa en su elaboración directamente y no sólo a través de la tradicional fórmula indirecta. Los últimos movimientos sociales evidencian la necesidad de alterar el modelo existente, y evolucionar hacia una etapa en la que las instancias políticas no sean los responsables únicos de las decisiones adoptadas ${ }^{28}$.

c) Coordinación y coherencia de las políticas comunitarias: La complejidad de las tareas emprendidas por la Unión, consecuencia del creciente número de Estados miembros y de la dificultad de las políticas emprendidas, y la mayor implicación de las autoridades regionales y locales exigen la primacía del principio de coherencia, como base para la adopción de decisiones efectivas y que respondan a las necesidades comunitarias, nacionales, regionales y locales. En este entramado complejo de Estados e instituciones las redes de información y comunicación adquieren una especial significación para proporcionar información a nivel nacional y local. Este intercambio de datos exige un doble canal de comunicación: la asunción de los entes locales como fuente de información sobre las necesidades y preocupaciones del ciudadano, a la vez que destino de los datos sobre las iniciativas y propuestas comunitarias, sin perjuicio del flujo directo de comunicación entre el ciudadano y las instituciones comunitarias.

d) Novedades en el proceso de decisión de las políticas comunitarias: La Comisión insta a los Estados miembros a elaborar mecanismos adecuados para incorporar la experiencia regional y local en el proceso de decisión de la política comunitaria. En la etapa del Libro Blanco de la Gobernanza ya se adoptaron propuestas que favorecían la participación de las regiones y los organismos locales en la adopción de contratos tripartitos por objetivos entre la Comisión, los Estados miembros y las regiones y organismos locales designados al efecto. A través de estos contratos las autoridades locales eran designadas para ejecutar acciones concretas con el fin de alcanzar los objetivos comunitarios específicos.

Los entes locales han ocupado una posición secundaria frente a otros niveles institucionales, fundamentada en la incapacidad de establecer un régimen de carácter descentralizado en el que primar la presencia del ciudadano en lugar de buscar la preponderancia de las instituciones. El resultado era una exigua autonomía local, mientras que las competencias que de forma natural debieran ejercer los entes locales se repartían a otros niveles organizativos; el interés del ciudadano quedaba relegado a un segundo plano ante la búsqueda de privilegios de las administraciones. Los nuevos modelos suponen una ruptura con este esquema centralista; el eje se traslada al ciudadano y su implicación en la política es la base para legitimar el poder de las instituciones. En la Reunión Informal de Málaga sobre la Gobernanza Multinivel en las futuras presidencias se incidió en la idea de garantizar la existencia de mecanismos que aseguren las relaciones entre los distintos niveles de gobierno, y de esta forma mejorar la participación de los Entes regionales y locales en la elaboración, puesta en práctica y evaluación de las políticas comunitarias ${ }^{29}$.

Los próximos pasos de la Unión Europea pasan inexorablemente por esta participación activa de los entes locales; en la propia Estrategia UE 2020 se afirma "Todas las autoridades nacionales, regionales y locales deberían ejecutar la colaboración, asociando estrechamente a parlamentos, interlocutores sociales y representantes de las organizaciones sociales, para contribuir a la elaboración de programas nacionales de reforma y a su aplicación. Al entablar un diálogo permanente entre varios niveles de Gobierno, las prioridades de la Unión se acercan a los ciudadanos, reforzando la asunción que se precisa para la aplicación de la Estrategia Europa 2020"30.

27 Como ejemplo de esta tendencia podemos citar el art. 10.1 del Estatuto de Autonomía de Andalucía, en el que se afirma: “La Comunidad Autónoma de Andalucía promoverá las condiciones para que la libertad y la igualdad del individuo y de los grupos en que se integra sean reales y efectivas; removerá los obstáculos que impidan o dificulten su plenitud y fomentará la calidad de la democracia facilitando la participación de todos los andaluces en la vida política, económica, cultural y social. A tales efectos, adoptará todas las medidas de acción positiva que resulten necesarias”. Sobre la regulación legal de la participación ciudadana, Tur Ausina, R., “Participación ciudadana. Oportunidad, necesidad y esencia de su regulación legal”, Revista Deliberación (Departamento de Presidencia del Gobierno de Aragón), núm. 1, 2010, pp. $19-41$.

28 Castel Gayán, S., op. cit. "Descentralización política...", p. 283: “Diversas comunidades autónomas han puesto en marcha auténticas políticas de innovación democrática y promoción de la participación ciudadana. Esta política se puede definir como el conjunto de iniciativas, procedimientos e instituciones creadas por los gobiernos para fomentar la participación de la ciudadanía y su inclusión en los procesos de toma de decisiones que les afectan. Un eje esencial de esta política es la renovación normativa, encaminada a la institucionalización de cauces propios de una democracia participativa que facilite una mayor influencia de la ciudadanía en los asuntos públicos. Asistimos en los últimos años a una profunda revisión legislativa con diferencias sustanciales entre las comunidades autónomas -como se irá viendo- pero que asume como tronco común el reconocimiento de un enfoque más proactivo de la participación, orientada al diálogo y la deliberación, la consulta, el intercambio de información y la resolución de conflictos de intereses".

29 Reunión Informal de Ministros de Política Territorial de la Unión Europea, convocada bajo el lema "Sumar esfuerzos para multiplicar resultados", y celebrada en Málaga los días 16 y 17 de marzo de 2010.

30 Estrategia Europa 2020, citada en nota al pie núm. 7, p. 31. 


\title{
IV. LA PROYECCIÓN EXTERIOR
}

El futuro de la administración local se encuentra en su proyección exterior, tanto a nivel de los municipios limítrofes como a nivel internacional. El asociacionismo municipal, materializado en la superación de los tradicionales límites administrativos y la configuración de nuevos modelos de administración local basados en estructuras supramunicipales, es una respuesta lógica a la cohesión natural que existe entre municipios colindantes. El fortalecimiento del gobierno local se asienta sobre una mayor autonomía respaldada por una mayor capacidad económica, y el asociacionismo local es un instrumento para superar las limitaciones competenciales y financieras de los municipios; la agrupación municipal frena la expansión de las políticas centralistas e instaura un modelo político con nuevos actores institucionales.

Los principios de la buena gobernanza reconocen la relevancia del ente local, que es designado como un sujeto clave en la toma de decisiones. Los modelos de coordinación y cooperación intermunicipal, a nivel nacional e internacional, suponen un paso más allá en el papel destacado de lo local. Nuevas fórmulas de comunicación basadas en las redes de diálogo y en proyectos comunes entre varias administraciones locales han inaugurado una política propia, ajena a las tendencias de los entes regionales y nacionales, y que debe primar el interés del ciudadano.

La Carta Europea de Autonomía Local expone con claridad las distintas modalidades de asociación de las que pueden disfrutar las administraciones locales ${ }^{31}$.

Art. 10.El derecho de asociación de las Entidades locales:

1. Las Entidades locales tienen el derecho, en el ejercicio de sus competencias, de cooperar y, en el ámbito de la Ley, asociarse con otras Entidades locales para la realización de tareas de interés común.

\begin{abstract}
2. El derecho de las Entidades locales de integrarse en una asociación para la protección y promoción de sus intereses comunes y el de integrarse en una asociación internacional de Entidades locales deben ser reconocidos por cada Estado.
\end{abstract}

\section{Las Entidades locales pueden, en las condiciones eventualmente previstas por la ley, cooperar con las} Entidades de otros Estados.

Los entes locales disponen de tres vías de actuación: la asociación con otros entes locales de su mismo Estado (coordinación municipal), la cooperación con Entidades de otros Estados (cooperación descentralizada) y la integración en una asociación nacional o internacional para la protección y defensa de sus intereses.

\section{Las asociaciones intermunicipales}

La configuración de una estructura administrativa supramunicipal favorece la defensa de los intereses locales y permite ejercer una mayor presión a los municipios, en especial a aquellos de escasos recursos y una escasa presencia a nivel regional y nacional. El fenómeno asociativo intermunicipal de carácter nacional constituye una evolución natural ante las necesidades comunes de los municipios vecinos. La coordinación municipal es una vía para superar las limitaciones municipales, en especial su escasa capacidad económica, y un instrumento para acometer empresas que beneficien a todas las poblaciones asociadas y que se encuentren fuera del alcance de los municipios aislados ${ }^{32}$.

31 La Carta Europea de Autonomía Local fue adoptada el 15 de octubre de 1985 en Estrasburgo, y ratificada por España el 20 de enero de 1988. En relación a esta disposición, Lasagabaster Herrarte, l., La carta europea de la autonomía local, lustel, Madrid, 2007. Sobre la difusión de la Carta Europea de Autonomía Local en otros Estados, "La forma de gobierno local y la circulación de los modelos en la Europa centrooriental”, Anuario del Gobierno Local. Configuración Jurídica de la Autonomía Local. Municipio y transformaciones sociales. Urbanismo e Inmigración, Instituto de Derecho Público, Barcelona, 2001, pp. 282. Sobre la aplicación de esta disposición, Marsal i Ferret, M., "Recomendación del Congreso de los Poderes Locales y Regionales de Europea sobre la democracia local y regional en España”, Anuario del Gobierno Local. La Ley de Modernización del Gobierno Local. Cooperación intermunicipal, Instituto de Derecho Público, Barcelona, 2003, pp. 357-368.

32 Como ha señalado Ferreira, A.X., "La cooperación municipal en España: los entes supramunicipales en el ordenamiento jurídico español”, Urban Public Economics Review, núm. 6, 2006, p. 70: “El de la cooperación es un principio de obligado cumplimiento para las administraciones locales. Con carácter general nuestro ordenamiento jurídico hace de él un principio general de aplicación a todas las administraciones, tal y como prescriben, entre otros, los artículo 4.4 de la Ley de régimen jurídico de las administraciones Públicas y del procedimiento administrativo común o los artículos 10.1 ó 57 de la Ley reguladora de las bases de régimen local, entre otros. Además, las especiales circunstancias de nuestros municipios provocan que sólo por medio de la colaboración y cooperación institucional se pueda lograr un eficaz y adecuado funcionamiento de los mismos. Su considerable fragmentación territorial, su limitada capacidad técnica para la gestión de muchos de los asuntos que le son propios o su notoria insuficiencia de recursos les obliga a cooperar y colaborar entre sí o con otras administraciones para poder prestar, por sí o asociados, los servicios que el propio legislador les ha impuesto como obligatorios (artículo 26 de la LBRL) y desarrollar las competen- 
La asociación de municipios favorece la visibilidad de los gobiernos locales, lo que contribuye a que puedan influir en mayor grado en las políticas regionales, estatales y comunitarias. No obstante, estas iniciativas deben enfrentarse a obstáculos como la escasez de recursos económicos, la falta de experiencia de los representantes locales y la ausencia de un respaldo suficiente por parte de las administraciones nacional y regional.

El marco normativo de los entes supramunicipales tiene como referencia la regulación constitucional y las leyes estatales y autonómicas. El texto constitucional, además de la organización territorial básica del Estado en municipios, provincias y Comunidades Autónomas, reconoce que se podrán crear agrupaciones de municipios distintas de las provincias. La Ley de Bases de Régimen Local da una respuesta a estas necesidades de asociación en el ámbito local con la regulación de las comarcas, las áreas metropolitanas y las mancomunidades de municipios.

Las comarcas se configuran como una entidad local con personalidad jurídica propia, creadas para la gestión de intereses comunes a varios municipios situados en una misma zona y que comparten caracteres y elementos definidores comunes, ya sean de índole económica, cultural o social. Los municipios integrados en una comarca conservan la competencia para la prestación de los servicios mínimos, y su capacidad de intervención en las competencias que con carácter general les atribuye la Ley estatal. Las Comunidades Autónomas son competentes para crear comarcas en su territorio y para delimitar su territorio y establecer organización, competencias y recursos económicos.

Las áreas metropolitanas responden a una realidad distinta, ya que atienden a las peculiaridades de los municipios de grandes aglomeraciones urbanas. Estas entidades supramunicipales integran municipios entre cuyos núcleos de población existen vinculaciones económicas y sociales que hacen necesaria la planificación conjunta y la coordinación de determinados servicios. Al igual que sucede con las comarcas, su regulación se establece en la legislación autonómica, imponiéndose únicamente en la legislación básica del Estado que todos los municipios estén representados en sus órganos de gobierno ${ }^{33}$.

Por último cabe mencionar a las mancomunidades de municipios, entidades de carácter asociativo y con personalidad jurídica propia que responden a la voluntad de los municipios de gestionar en común servicios u obras de su competencia34. A pesar de que su proceso de creación viene previsto en la Ley, cada mancomunidad aprueba sus estatutos en los que deben constar la denominación, su ámbito de aplicación territorial, su finalidad, las competencias que se le atribuyen, así como sus órganos de Gobierno, reglas de funcionamiento y régimen económico.

Las asociaciones intermunicipales adquieren una nueva relevancia en un contexto de crisis económica en el que una de las prioridades de cualquier Administración es racionalizar el gasto. Los datos del Instituto Nacional de Estadística revelan que en España existen 8.116 municipios ${ }^{35}$; más de la mitad tiene menos de un millar de habi-

cias que les han sido atribuidas (art. 25 de la LBRL), so pena de no cumplir con el mandato constitucional de servir con objetividad y eficacia a los intereses de la comunidad (artículo 103 CE)".

García Rubio, F., “Ámbito de actuación de las comarcas”, Revista General de Legislación y Jurisprudencia, núm. 1, 2008, pp. 45-110; Torres Cobas, F., "Perversiones y novedades de la cooperación municipal”, Anuario del Gobierno Local. La Ley de Modernización del Gobierno Local. Cooperación intermunicipal, Instituto de Derecho Público, Barcelona, 2003, pp. 259-290.

33 La Ley de Demarcación Municipal de Andalucía, 7/1993 de 27 de julio, ha sido la encargada de establecer los requisitos de estas Entidades en el ámbito de la Comunidad Autónoma de Andalucía. Esta norma define a las áreas metropolitanas en el art. 43 en los siguientes términos: “Entidades Locales Supramunicipales, con personalidad jurídica propia y plena capacidad para el ejercicio de sus competencias integradas por municipios de grandes aglomeraciones urbanas entre cuyos núcleos de población existen vínculos urbanísticos, económicos, y sociales que se constituyen como división territorial óptima para la planificación conjunta y la gestión coordinada de determinadas obras y servicios".

En lo que respecta al marco competencial, la norma andaluza dispone: "Serán competencia de las áreas metropolitanas aquellas materias que, siendo del interés propio de la colectividad de su territorio, contribuyan a satisfacer sus necesidades y aspiraciones, como son las enumeradas en el párrafo segundo del artículo 25 de la Ley reguladora de las Bases del Régimen Local y se determinen en la Ley creadora del respectivo ente metropolitano; 2 . Para el ejercicio de sus competencias tendrán como funciones generales la planificación conjunta y la coordinación, control y gestión de aquellos servicios municipales que por las características económicas, sociales y urbanas concurrentes en los respectivos ámbitos territoriales hagan necesaria una actuación de carácter supramunicipal”.

Como ha señalado Sánchez Blanco, en “Modernización del gobierno local y gobernanza europea”, Revista Jurídica de Castilla y León, núm. 1, septiembre de 2003, p. 206: “Comarcas y Áreas Metropolitanas son las figuras asociativas de los Entes Locales, ineludibles para materializar la cohesión económica, social y territorial, en las Comunidades Autónomas, en el Estado español y en el conjunto de la Unión Europea, mediante la coherente contribución asociativa de los mismos Entes Locales, que pueden y deben proyectar específicas alternativas en la aplicación de los Fondos Estructurales y en el desarrollo de las Redes Transeuropeas y, con ello contribuir decisivamente a materializar la identidad europea".

34 La regulación de las Mancomunidades de Municipios sufrió modificaciones tras la adopción de la Ley 57/2003 de Modernización del Cobierno Local, en la Exposición de Motivos de esta norma se establecía: "Dentro de este primer bloque de medidas, se refuerza el papel de las mancomunidades de municipios de nuestro sistema local, de forma que, por una parte, se mejora la regulación de sus potestades, aclarando que su determinación, en el marco de la legislación aplicable a cada una de ellas, corresponde a los municipios mancomunados, y, por otra parte, estableciendo la posibilidad de que puedan crearse entre municipios de distintas Comunidades Autónomas, en los términos de sus legislaciones respectivas".

35 En los últimos años se han creado nuevos municipios en España, entre los que podemos citar: El Pinar de El Hierro (Santa Cruz de Tenerife), Vegaviana, Alagón del Río (Cáceres), Villanueva de la Concepción (Málaga) y La Canonja (Tarragona). De estos nuevos municipios, los 
tantes y alrededor de mil municipios no alcanzan el centenar de vecinos. Estos pequeños municipios no disponen de recursos suficientes para hacer frente a sus competencias por lo que la asociación con municipios vecinos con idénticas o similares dificultades se convierte en una solución efectiva para la gestión de servicios, como la recogida de residuos o la depuración de aguas.

El espíritu localista y las tradicionales rivalidades entre municipios colindantes se encuentran en la raíz de buena parte de los obstáculos para la adopción de modelos de asociacionismo. Sin embargo, ante las dificultades de financiación de los entes locales debe adoptarse algún modelo de solución si no se quiere llegar al caso extremo de Grecia, que como respuesta al caos económico que ha sufrido ha eliminado 679 consistorios, lo que le ha supuesto un ahorro estimado de 1.185 millones de euros ${ }^{36}$. A esta realidad cabe sumar el debate que se ha abierto sobre la eficacia real de las Diputaciones Provinciales y su función como apoyo a los pequeños municipios y como instancia intermedia entre el ámbito municipal y el autonómico.

Desde las instituciones comunitarias se está realizando una apuesta clara por el incentivo de los ámbitos políticos supralocales y los gobiernos locales intermedios. En el ámbito de la cohesión económica la generación de entornos locales competitivos y creativos se convierte en una premisa básica para el desarrollo económico local; la elaboración de estrategias para la atracción de talento y la mejora de la competitividad se orientan hacia el "desarrollo endógeno" y la adopción de medidas económicas proactivas para aprovechar los recursos de cada territorio. La lógica competencia entre territorios se combina con una indispensable cooperación, en la que juegan un papel determinante las agrupaciones intermunicipales, que permita sumar posibilidades y realizar una labor de crítica constructiva para alcanzar la máxima efectividad ${ }^{37}$.

\section{Perspectiva internacional: la administración local más allá de las fronteras nacionales}

La atención al ciudadano y la presencia global constituyen el desafío de la administración local, es decir, la perspectiva tradicional del municipio como eje político básico y extremo último de vinculación entre la población y los poderes públicos, y la perspectiva internacional ligada desde siempre a la actuación de los gobiernos nacionales. Reforzar los entes locales en su estructura interna y en su dimensión externa son las vías para el derecho municipal de los próximos años.

El espíritu de las iniciativas de cooperación descentralizada es el enriquecimiento mutuo a través del intercambio de experiencias ${ }^{38}$. En este sentido se puede afirmar que la cooperación internacional en el ámbito local dispone de una singularidad propia frente a la cooperación internacional desarrollada por los Estados. Los modelos de gobierno local disponen de una capacidad de actuación limitada, y unas competencias y autonomía que se concentran en pequeños territorios, que no tienen parangón con el potencial de los Estados y su capacidad de actuación a nivel internacional. Esta concreción del poder local se vincula con su principal característica: su cercanía al ciudadano y a sus problemas diarios. Las agendas internacionales de los Estados se alejan de la vida real del ciudadano para centrarse en la problemática de los propios Estados, mientras que la cooperación a nivel local es capaz de actuar directamente y de una forma sencilla sobre las necesidades reales de una localidad 39 .

dos pertenecientes a la provincia de Cáceres, Vegaviana y Alagón del Río, no superan los mil habitantes.

36 A fines del s. XX otros Estados europeos también adoptaron esta drástica decisión, así Suecia redujo en un $87 \%$ el número de municipios, Reino Unido en un $76 \%$ y Dinamarca en un $80 \%$. Trillas, A., "Suprimir municipios, misión imposible", Diario El País, 28 de julio de 2010 , pp. 24 y 25.

37 Agenda de Barcelona, Hacia una Agenda Local Europea, Cumbre Europea de Gobiernos Locales celebrada entre el 22 y el 24 de febrero de 2010, bajo el lema "Gobiernos locales en red para una nueva Europa".

38 Badia i Dalmases, F., "Los Gobiernos locales en la acción exterior. Una visión desde Cataluña”, Documentos CIDOB, núm. 5, septiembre de 2009, p. 24. Este autor enumera las ventajas que presenta la cooperación descentralizada cuando es capaz de desarrollar todo su potencial: “-operadores nuevos y más flexibles; -mejores opciones de participación ciudadana; -mejor aprovechamiento de su capacidad vinculante entre las comunidades del Norte y del Sur; -disminución del número de mediadores que gestionan las iniciativas; -colocación de los agentes en el centro mismo de ejecución y traspaso de responsabilidades; -mejora de la adaptación de las operaciones a las necesidades locales; -incremento de la apropiación local y de la credibilidad; -estimulación de la participación de las entidades subestatales en el campo de las relaciones internacionales; -incremento de la durabilidad de las acciones y mejor planificación”. Romero, M., “Una aproximación contextual y conceptual a la Cooperación Descentralizada", en Tejiendo Lazos entre Territorios. La Cooperación Descentralizada Local UE-América Latina, Diputació de Barcelona, Municipalidad de Valparaíso, 2004. Malé, J., Especificidades de la cooperación descentralizada pública: actores, contenidos y modelos, Observatorio de la Cooperación Descentralizada Unión Europea América Latina, Montevideo, Marzo, 2006.

39 Laroca Cervigón, F. y Ferrer Matvieychuc, G., "Valencia y Barcelona ante el desarrollo sostenible. ¿Sustentabilidad o marketing ambiental?”, Ágora. Revista de Ciencias Sociales, núm. 11, 2004, pp. 55, afirman: “En el contexto de la globalización, las ciudades (principalmente las grandes regiones metropolitanas) se han convertido en espacios centrales para el crecimiento económico, la acumulación de capital y la competitividad. En ellas se concentran las competencias, capacidades, conocimientos, infraestructuras (de transporte y comunicaciones) que son vitales para la expansión y desterritorialización de los mercados (de factores, productos) y de las funciones de producción y comercialización de las empresas (... La ciudad ya no es el espacio privilegiado de la producción, como lo fuera para el capitalismo industrial, sino que deviene en un espacio diseñado para la valorización del capital global”.

Marx, V., Tesis Doctoral: Las ciudades como actores políticos en las relaciones internacionales, Barcelona, julio de 2008, p. 67,: “En el mundo contemporáneo se ha estudiado la relación entre lo global y lo local para justificar el papel de la ciudad en la dinámica globalizadora. El lugar, el territorio o el espacio demarca do por el ámbito urbano están más cerca de los ciudadanos, pueden rescatar elementos como la identidad 
La cooperación descentralizada se centra en la actualidad en la cooperación al desarrollo; mediante su participación en este tipo de iniciativas los agentes locales se han posicionado en la línea del apoyo a poblaciones desfavorecidas de otros Estados. Motivados por situaciones de crisis concretas, como inundaciones, terremotos u otro tipo de tragedias, o bien vinculados a servicios en los que las poblaciones presentan deficiencias importantes como la sanidad o la educación, los proyectos de este modelo de cooperación internacional se han centrado en una relación unidireccional. La simetría, el diálogo, el aprender unos de otros, se ha reducido a la transferencia de recursos económicos, materiales y personal cualificado; el intercambio no existe en este modelo de actuación.

La competencia genérica que atribuye el artículo 25 de la LBRL a los municipios para "promover toda clase de actividades y prestar cuantos servicios contribuyan a satisfacer las necesidades y aspiraciones de la comunidad vecinal", constituyen el título habilitante para el ejercicio de actuaciones en el ámbito de la cooperación al desarrollo. Título que se concreta en el texto de la Ley 23/1998, de 7 de julio, de Cooperación Internacional al Desarrollo, que reconoce la actuación en este ámbito de las Comunidades Autónomas y los Entes locales, basada en los principios de autonomía presupuestaria y autorresponsabilidad ${ }^{40}$.

Buena parte de las Comunidades Autónomas españolas también han elaborado su propia regulación sobre esta materia, y han incidido en la necesidad de implicar a los entes locales en la cooperación al desarrollo, si bien cada texto ha abordado este principio desde una perspectiva. De esta forma, la ley andaluza opta por fomentar la colaboración con los entes locales e integrarlos en el Consejo Andaluz de Cooperación Internacional para el Desarrollo ${ }^{41}$. Mientras que la norma canaria se decanta por la creación, a instancia de las entidades locales, del Fondo Canario Local de Cooperación Internacional al Desarrollo, cuya finalidad será fortalecer las acciones de cooperación que se realicen en la Comunidad Autónoma y aumentar la eficiencia de los recursos locales destinados a este fin. La ley canaria también establece que el Fondo podrá recibir aportaciones de la Administración Pública de la Comunidad Autónoma4².

Otras Comunidades Autónomas también han desarrollado esta materia, desde la Comunidad Autónoma de Madrid que fue pionera con la elaboración de su Ley en 1999, hasta las disposiciones elaboradas por Cataluña, País Vasco, Comunidad Valenciana, Galicia, Castilla y León, Aragón, Castilla-La Mancha, Murcia, Asturias, Cantabria, Extremadura, La Rioja, Navarra e Islas Baleares ${ }^{43}$. La norma catalana destaca por la implicación que realiza a lo largo de todo el articulado de las entidades locales, así se pone de manifiesto en la enumeración de los valores, finalidades y principios ordenadores que van a inspirar la actividad de la Administración de la Generalitat y de los entes locales en materia de cooperación al desarrollo y solidaridad internacional ${ }^{44}$.

También destaca la creación de la Comisión de Coordinación con los Entes locales catalanes, que tiene por fin el impulso de la "información y la comunicación, la colaboración, la cooperación y la asistencia en la ejecución recíproca de las actuaciones de cooperación al desarrollo de la Administración de la Generalitat y de los entes locales”45.

y reivindicar el papel de lo local frente a lo global. El interés por el conocimiento y la cultura local, la política del "lugar" y de "construcción del lugar" está muy extendido (...) De la relación global-local nace, en la década de los noventa, el concepto de paradiplomacia (Soldatos, 1990; Feldman y Feldman, 1990; Jeffery, 1997). La paradiplomacia constituye un fenómeno nuevo e importante dentro de las teorías sobre el regionalismo y las relaciones internacionales, y retrata la capacidad de influencia política de los actores locales".

Cerrillo i Martínez, A., "La ayuda al desarrollo y los Entes Locales", Anuario del Gobierno Local. Configuración Jurídica de la Autonomía Local. Municipio y transformaciones sociales. Urbanismo e Inmigración, Instituto de Derecho Público, Barcelona, 2001, p. 315. Como señala este autor: "la cooperación al desarrollo de los Entes Locales debe realizarse con una clara especialización que se deriva directamente de su experiencia diaria. En particular, dada la experiencia de los Entes Locales en España, la cooperación de los Entes Locales podría abordar, entre otros, los siguientes ámbitos: descentralización, fortalecimiento institucional y desarrollo local”.

40 Art. 20 de la Ley 23/1998 de 7 de julio, de Cooperación Internacional al Desarrollo. En el segundo párrafo de este precepto se afirma que la acción de las Comunidades Autónomas y los Entes locales debe "respetar las líneas generales y directrices básicas establecidas por el Congreso de los Diputados a que se refiere el artículo 15.1 de la presente Ley y el principio de colaboración entre Administraciones públicas en cuanto al acceso y participación de la información y máximo aprovechamiento de los recursos públicos". A este respecto, Cerrillo i Martínez, op. cit., pp. 303 y ss.

41 Arts. 10, 13 y 17 de la Ley 14/2003, de 22 de diciembre, de Cooperación Internacional para el Desarrollo de Andalucía.

42 Art. 22 de la Ley 4/2009, de 24 de abril, de Cooperación Internacional para el Desarrollo de Canarias. En el apartado 5.1.3 del Plan Director de la Cooperación Canaria para el desarrollo (2010-2013), se afirma que "es necesaria y básica lograr una progresiva incorporación de las entidades locales a las actividades de cooperación para el desarrollo", p. 25.

43 Ley 13/1999, de 29 de abril, de Cooperación al Desarrollo de Madrid; Ley 26/2001, de 31 de diciembre, de Cooperación al Desarrollo de Cataluña; Ley 1/2007, de 22 de febrero, de Cooperación para el Desarrollo del País Vasco; Ley 6/2007, de 9 de febrero, de Cooperación al Desarrollo de Comunidad Valenciana; Ley 3/2003, de 19 de junio, de Cooperación al Desarrollo de Galicia; Ley 9/2006, de 10 de octubre, de cooperación al desarrollo de Castilla y León; Ley 10/2000, de 27 de diciembre, de Cooperación al Desarrollo de Aragón; Ley 3/2003, de 13 de febrero, de Cooperación al Desarrollo de Castilla-La Mancha; Ley 4/2006, de 5 de mayo, de Cooperación al Desarrollo de Asturias; Ley 4/2007, de 4 de abril, de Cooperación al Desarrollo de Cantabria; Ley 9/2005, de 21 de junio, de Cooperación para el Desarrollo de Illes Balears; Ley 1/2003, de 27 de febrero, de Cooperación para Desarrollo de Extremadura; Ley 12/2007, de 27 de diciembre, de Cooperación Internacional para el Desarrollo de Murcia; Ley 4/2002, de 1 de julio, de Cooperación al Desarrollo de La Rioja de 2002.

44 Arts. 3, 4 y 6 de la Ley 26/2001, de 31 de diciembre, de Cooperación al Desarrollo de Cataluña.

45 Art. 23 de la Ley 26/2001, de 31 de diciembre, de Cooperación al Desarrollo de Cataluña. 
La cooperación al desarrollo es una realidad que, sin duda, debe formar parte de la cooperación descentralizada pero no es su única vía de actuación. Es evidente que la implicación de los agentes locales en la ayuda a estas localidades con menos recursos o situaciones de crisis es laudable en todos los sentidos, pero se debe avanzar un paso más. Esta cooperación al desarrollo puede servir como primer paso, acercamiento inicial a otros modelos de gobiernos locales, a otras realidades locales con las que se debe potenciar el intercambio de experiencias bilateral.

Estas propuestas no son novedosas, a mediados del siglo pasado ya existían iniciativas para el fomento de la cooperación internacional a nivel municipal en esta línea. En el Primer Congreso Iberoamericano de Municipios, celebrado en Junio de 1955 en Madrid, ya se hace referencia a esta realidad en los siguientes términos: "La ponencia cuarta recibió el título de "Cooperación intermunicipal entre los países hispánicos" y fue redactada conjuntamente por el Instituto de Cultura Hispánica y por el Instituto de Estudios de Administración Local. Parten del supuesto real de la existencia de un movimiento de internacionalización municipalista que merece ser aprovechado en el ámbito hispanista mediante la creación en cada gran capital de los pueblos hermanos de una institución que con el nombre de Casa Hispánica o Casa de Iberoamérica atienda, acoja y auspicie las actividades culturales propias de la ciudad, las presente y ofrezca al mundo exterior, y recoja las mejores iniciativas de las demás ciudades hispanas" ${ }^{46}$. Este modelo de cooperación se encontraba favorecido por la estrecha relación entre los países Iberoamericanos, y la vinculación cultural que les une.

El potencial de la cooperación descentralizada permite superar las limitaciones de las relaciones interestatales, es una oportunidad para entablar una relación de simbiosis entre administraciones locales situadas geográficamente en distintos puntos del planeta pero que pueden desarrollar una política coordinada que permita alcanzar, de forma directa y sin intermediarios el bienestar de su población. Las comunidades locales no se encuentran condicionadas por las limitaciones de las relaciones interestatales, la cooperación descentralizada permite un contacto directo entre gobiernos locales que se encuentran marcados por un condicionante común: la finalidad de dar una respuesta rápida y eficaz a las demandas del ciudadano. El carácter horizontal de la relación entre entes locales permite superar las barreras que existen en las relaciones estatales, marcadas por la preponderancia de un Estado sobre otro, y por tanto condicionadas por su carácter vertical. La relación entre entes locales de distintos Estados es una oportunidad de enriquecimiento mutuo que no puede constreñirse a una ayuda unilateral; quizás este apoyo puntual ante una catástrofe natural o ante necesidades concretas en ciertos sectores puede ser el primer impulso para establecer una relación fluida y recíproca

La cooperación descentralizada engloba la dimensión internacional de la actuación local; el concepto cooperación descentralizada se basa en la colaboración y el intercambio de experiencias, un sistema para crear entornos de diálogo en los que conocer nuevas fórmulas para afrontar los retos actuales. La cooperación descentralizada es un ejemplo de la vinculación entre lo local y lo global, y de la capacidad de los entes locales para llevar a cabo actuaciones conjuntas con territorios físicamente alejados pero con un conjunto de intereses similares, aún cuando presenten diferencias sociales, económicas, culturales, ambientales o tecnológicas ${ }^{47}$.

La perspectiva internacional de los entes locales representa nuevos desafíos para la creación de redes locales para la cooperación descentralizada. La cooperación al desarrollo es uno más de los componentes que deben ser integrados en las redes de diálogo local de carácter internacional. Las diferencias económicas entre las distintas administraciones locales implicadas no debe transformar la cooperación descentralizada en un instrumento paternalista y condescendiente en el que un grupo de municipios trate de exportar su modelo de actuación. La generación de un entorno de diálogo en el que elaborar proyectos comunes con aportaciones equilibradas entre todos los sujetos implicados equivale a una efectiva red local $4^{8}$.

\section{La experiencia de la Unión Europea}

La actuación de las instituciones comunitarias en el ámbito de la cooperación transnacional se ha centrado en tres niveles de actuación complementarios: la cooperación entre los Estados miembros de la Unión, la cooperación con los Estados candidatos a formar parte de la UE y la cooperación con otros Estados.

La Unión Europea también ha centrado sus esfuerzos en el apoyo de la buena gobernanza más allá de sus fronteras, en este sentido se pronunció la Comisión en su Comunicación Gobernanza y Desarrollo en donde se ex-

46 A.C.M., Revista de Administración Pública, núm. 18, 1955, pp. 315-318.

47 Eckersley, R., The Green State. Rethinking Democracy and Sovereignty, The MIT Press, Cambridge Massachusetts, 2004, pp. 250 y ss; Mol, A., Globalization and Environmetal Reform, The MIT Press, Cambridge Massachusetts, 2004, pp. 109 y ss.

48 Como señala Natera Peral, op. cit., p. 158: "la idea de gobernanza se vincula de forma predominante a la de gestión de redes: se está produciendo una transformación en los roles de las autoridades estatales en el paso del ejercicio jerárquico ("gobierno") a la gestión de redes de actores individuales o colectivos de diversa naturaleza ("gobernanza"). En las redes de políticas, el Estado y la sociedad civil se acoplan de modo flexible, y la interacción en el interior de la red puede producir un consenso negociado que facilita la formación de una política, para que en el momento de su aplicación encuentre más aceptación que resistencia”. 
ponía el vínculo entre la gobernanza y las políticas orientadas a la erradicación de la pobreza, la democratización y la seguridad mundial. La Comisión adopta en este texto un concepto amplio de gobernanza que alude a la capacidad del Estado de servir a los ciudadanos, en base a este concepto "la gobernanza se refiere a las normas, procesos y conductas a través de los que se articulan intereses, se gestionan recursos y se ejerce el poder en la sociedad. Lo fundamental, en este contexto, es la manera en que se desempeñan las funciones públicas, se gestionan los recursos públicos y se ejercen las facultades normativas públicas"49. Con posterioridad, en el año 2006, la Comisión elaboró una nueva Comunicación en la que sostenía que todos los niveles de gobernanza son importantes (local, nacional e internacional), pero subraya el papel esencial que pueden desempeñar las autoridades locales en la consecución de los Objetivos de Desarrollo del Milenio ${ }^{50}$.

La cohesión económica, social y territorial y la solidaridad entre los Estados miembros constituyen una prioridad de la Unión Europea ${ }^{51}$. El Fondo Social Europeo, el Fondo Europeo de Desarrollo Regional y el Fondo de Cohesión son instrumentos para lograr un desarrollo común en todo el territorio comunitario, favoreciendo la inclusión de las regiones más desfavorecidas. Las políticas de cohesión animan a las regiones y ciudades de los distintos Estados de la Unión a trabajar juntos y aprender unos de otros. Para el periodo 2007-2013, el objetivo de cooperación territorial de la Unión Europea se desarrolla en tres tipos de programas: cooperación en zonas fronterizas, cooperación transnacional y cooperación interregional52.

La cooperación transnacional se sitúa entre las políticas sociales de la Unión Europea y favorece el intercambio de conocimientos, ideas novedosas, experiencias, etc. En esta línea se han potenciado los proyectos nacionales y regionales, y en menor medida las iniciativas locales, si bien las últimas propuestas adoptadas tratan de potenciar una mayor presencia local en estas actuaciones. La principal virtualidad de esta iniciativa es su carácter múltiple, ya que no se trata de presentar un modelo de actuación si no de implicar a todos los organismos que participen en la elaboración de nuevos esquemas de actuación, creados de forma multilateral, en lugar de unilateral.

Las redes regionales y urbanas han alcanzado una gran relevancia para establecer lazos entre los propios Estados miembros, con los países candidatos y con el resto del mundo, y son un instrumento destacado para la integración europea. El Libro Blanco de la Gobernanza ha destacado su potencial y ha puesto de relieve la oportunidad de apoyar estas iniciativas ante los beneficios que generan. Como ha afirmado la Comisión Europea: "La política de cohesión, como principal fuente de inversiones comunitarias en la economía real, proporciona un considerable apoyo a las inversiones públicas, también a nivel regional y local. Es la expresión más importante de la solidaridad europea y su objetivo es ayudar a los ciudadanos europeos más necesitados"s3.

Estas iniciativas de la Unión Europea también han tenido su respuesta a nivel nacional; en la última fase de las reformas, ya se incorporaron en los distintos Estatutos de Autonomía referencias a la cooperación en el ámbito de

49 Comunicación al Consejo, al Parlamento Europeo y al Comité Económico y Social sobre Gobernanza y Desarrollo, citada en nota al pie núm. 5, párrafo 4

50 Comunicación al Consejo, al Parlamento Europeo y al Comité Económico y Social "La gobernanza en el consenso europeo sobre política de desarrollo. Hacia un enfoque armonizado en la Unión Europea, citada en nota al pie núm. 5.

51 Bradley, J., “Evaluating the impact of European Union Cohesion policy in less-developed countries and regions", Regional Studies 40, 2006, pp. 189-199; Rubiera Morollón, F., “Nuevas orientaciones estratégicas de la política de cohesión de la Unión Europea: una revisión de posibles acciones adaptadas al nuevo enfoque”, Revista de Estudios Regionales, núm. 81, 2008, pp. 77-109.

En las Conclusiones finales alcanzadas en la Reunión Informal de Ministros sobre Política Regional, ya citada en la nota 25, se afirma: “La cohesión territorial es un elemento clave para poner de relieve cuáles deben ser las relaciones entre los territorios europeos y cómo se posicionan en su propio espacio y en el conjunto de regiones europeas en temas como la competitividad, la conectividad o la sostenibilidad. Para alcanzar una política de cohesión "sobre el terreno", las autoridades regionales y locales deben adquirir una mayor implicación en la gestión de estas políticas, considerando las competencias de las que son titulares y que contribuirán directamente a la consecución de los objetivos de la Estrategia 2020. Así pues, el concepto de cohesión territorial supone un avance cualitativo relevante, en tanto aporta énfasis a la política regional europea en aspectos como el autogobierno y una buena gobernanza que facilite la cooperación entre los distintos niveles de gobierno. Por ello, debemos asegurar la necesaria asociación de los poderes regionales y locales con el proceso de definición y puesta en marcha de las políticas de la Unión Europea como elemento de cohesión económica, social y territorial”. En este sentido debemos señalar que en la Estrategia Europa 2020, se proponen tres prioridades que se refuerzan mutuamente: “-Crecimiento inteligente: desarrollo de una economía basada en el conocimiento y la innovación; -Crecimiento sostenible: promoción de una economía que haga un uso más eficaz de los recursos, que sea más verde y competitiva; -Crecimiento integrador: fomento de una economía con alto nivel de empleo que tenga cohesión social y territorial".

Sobre el futuro de la política de cohesión europea, Comisión Europea, Política de cohesión 2014-2020. Inversión en el crecimiento y el empleo, Oficina de Publicaciones de la Unión Europea, Luxemburgo, 2011.

52 Comunidades Europeas, Fondo Social Europeo. Invertir en las personas, Oficina de Publicaciones Oficiales de las Comunidades Europeas, Luxemburgo, 2007. Para más información sobre las iniciativas de cooperación territorial de la Unión Europea: http://ec.europa.eu/ regional_policy/cooperation/index_en.htm

Comisión Europea, European Territorial Cooperation. Building bridges between people, Oficina de Publicaciones de la Unión Europea, Luxemburgo, 2011.

53 Comisión Europea, Comunicación "Política de cohesión: invertir en la economía real”, COM(2008) 876 final, de 16 de diciembre de 2008, p.1. 
la Unión Europea. En esta línea podemos citar el Estatuto de Autonomía de Andalucía, que incluye dos preceptos que regulan las relaciones con las regiones europeas y la cooperación interregional y transfronteriza. El artículo 239 dispone que "la Junta de Andalucía promoverá la cooperación, y establecerá las relaciones que considere convenientes para el interés general de Andalucía, con las regiones europeas con las que comparta objetivos e intereses", previsión que se completa con la referencia al artículo 246 donde se afirma que "la Junta de Andalucía promoverá la formalización de convenios y acuerdos interregionales y transfronterizos con regiones y comunidades vecinas en el marco de lo dispuesto en la Constitución, los Estatutos de Autonomía y la normativa europea de aplicación". En este mismo sentido se expresan otros Estatutos de Autonomía, entre los que podemos señalar el artículo 62.4 de la Ley orgánica 1/2006, de Reforma del Estatuto de Autonomía de la Comunidad Valenciana en el que se afirma que la Generalitat, previa autorización de Les Corts, podrá establecer convenios de colaboración de gestión y prestación de servicios con otras regiones europeas. La reforma de 2007 del Estatuto de Autonomía de las Islas Baleares también dispone que la Comunidad Autónoma puede promover la cooperación con regiones de otros Estados con los que comparta intereses económicos, sociales o culturales. Mientras que el art. 197 de la Ley orgánica 6/2006, de 19 de julio, de reforma del Estatuto de Autonomía de Cataluña establece que "la Generalitat debe promover la cooperación con regiones europeas con las que comparte intereses económicos, sociales, ambientales y culturales, y debe establecer las relaciones que correspondan" 54 .

A la vista de estas disposiciones estatutarias conviene precisar la necesaria relación entre la proyección exterior de las Comunidades Autónomas y los Entes locales 55 . El propio Tribunal Constitucional ha tenido la oportunidad de pronunciarse al respecto en su Sentencia 31/2010, de 28 de junio, sobre el Estatuto de Autonomía de Cataluña. En concreto el Tribunal afirma en el fundamento jurídico 128: "El art. 199 EAC dispone que "la Generalitat debe impulsar y coordinar, en el ámbito de sus competencias, las acciones exteriores de los entes locales y de los organismos y otros entes públicos de Cataluña, sin perjuicio de la autonomía que tengan". Se objeta al precepto, según una genérica argumentación, que vulnera la autonomía local, con remisión a las alegaciones efectuadas con ocasión de la impugnación de los títulos II y IV del Estatuto. Es suficiente la lectura del precepto para advertir que expresamente deja a salvo la autonomía de los entes locales y de los organismos y otros entes públicos cuyas acciones exteriores debe impulsar y coordinar la Generalitat, de modo que, a falta de una más fundada argumentación, debe desestimarse, sin más, la tacha de inconstitucionalidad que se dirige al art. 119 EAC". Por tanto, el Tribunal Constitucional admite la labor de coordinación autonómica en la actuación exterior de los entes locales, que será compatible con la autonomía de los mismos para el desarrollo de sus competencias a través de su proyección internacional.

En el mismo sentido es oportuno comentar el pronunciamiento del Tribunal Constitucional en la misma Sentencia, en relación al art. 198 del Estatuto de Autonomía de Cataluña; en el fundamento jurídico 127 se establece: "El reproche que los Diputados recurrentes dirigen al art. 198 EAC radica en que, a su juicio, la amplitud del precepto conlleva a atribuir a la Generalitat la condición de sujeto de Derecho internacional, lo que es contrario a la Constitución. En el antecedente 117 se recoge la posición de los actores y de las demás partes. El precepto, como señala el Abogado del Estado, se circunscribe especialmente a la participación de la Generalitat en organismos internacionales de carácter cultural, como resulta de su propio tenor, según el cual "[I]a Generalitat debe participar en los organismos internacionales competentes en materias de interés relevante para Cataluña, especialmente la UNESCO y otros organismos de carácter cultural, en la forma que establezca la normativa correspondiente". En todo caso la participación de la Generalitat, como resulta del inciso final, queda condicionada a lo que disponga la normativa correspondiente, esto es, tanto la del organismo internacional del que se trate como la que dicte el Estado en el ejercicio de la competencia que le reserva el art. 149.1.3 CE. Del enunciado del precepto no cabe deducir, en consecuencia, la atribución a la Generalitat de la condición de sujeto de Derecho internacional, cualidad que ex art. 149.1.3 CE no cabe predicar de los entes territoriales dotados de autonomía política (STC 165/1994, de 26 de mayo, F. 5). En consecuencia, por las razones expuestas, ha de ser desestimada la impugnación del art. 198 EAC".

En este fundamento, al igual que en las valoraciones que realiza el Tribunal en los fundamentos 125 y 129 , se pone de relieve el siguiente eslabón en la perspectiva internacional, que en este caso relaciona las competencias de las Comunidades Autónomas y de la Administración General del Estado; a este propósito recuerda el Tribunal que las Comunidades Autónomas no son sujetos de derecho internacional, y que su participación en los organismos internacionales quedará supeditada a lo dispuesto en la normativa reguladora de los propios organismos

54 Ley orgánica 1/2006, de 10 de abril, de Reforma de la Ley Orgánica 5/1982, de 1 de julio, de Estatuto de Autonomía de la Comunidad Valenciana (BOE núm. 86, de 11 de abril de 2006); art. 103 de la Ley orgánica 1/2007, de 28 de febrero, de reforma del Estatuto de Autonomía de las Islas Baleares (BOE núm. 52, de 1 de marzo de 2007); Ley orgánica 6/2006, de 19 de julio, de reforma del Estatuto de Autonomía de Cataluña (BOE núm. 172, de 20 de julio de 2006).

55 Pons Ràfols, X., "La acción exterior de la Generalitat en la Sentencia del Tribunal Constitucional sobre el Estatuto de Autonomía de Cataluña”, Revista Catalana de Dret Públic, Especial Sentencia sobre el Estatuto, 2010, pp. 417-418. 
internacionales, y a las disposiciones estatales en desarrollo del art. 149.1.3 del texto constitucional. En consecuencia el marco de actuación internacional de los Entes locales estaría condicionado, de un lado por las disposiciones estatales y en segundo lugar por las iniciativas autonómicas de coordinación.

\section{Las Agrupaciones Europeas de Cooperación Territorial}

La necesidad de articular mecanismos de cooperación territorial que superaran las fronteras estatales ya se puso de manifiesto en las últimas décadas del siglo pasado. En esta línea se elaboraron las disposiciones sobre cooperación transfronteriza en el seno del Consejo de Europa; así nos encontramos con el Convenio-Marco Europeo sobre cooperación transfronteriza entre, Comunidades o Autoridades Territoriales de 21 de mayo de $1980^{56}$. Las iniciativas de cooperación transfronteriza se multiplicaron desde la elaboración de esta disposición y en nuestro país surgieron la Comunidad de Trabajo de los Pirineos Comunidad de Trabajo Galicia-Norte de Portugal ${ }^{57}$.

En el año 2006, la Unión Europea adoptó el Reglamento 1082/2006 del Parlamento Europeo y del Consejo, de 5 de julio de 2006, sobre la Agrupación Europea de Cooperación Territorial (AECT). Siguiendo la definición de la Cumbre sobre Cooperación Territorial Europea de $2010^{58}$, el Reglamento configura las AECTs como agrupaciones integradas por entidades situadas en el territorio de al menos dos Estados miembros pertenecientes a una o más de las siguientes categorías: Estados miembros, autoridades regionales, autoridades locales y organismos regidos por el Derecho público. También establece que dichas AECTs tienen por objeto facilitar y fomentar entre sus miembros la cooperación transfronteriza, transnacional e/o interregional, con el fin exclusivo de reforzar la cohesión económica y social ${ }^{59}$.

La AECT favorece que los entes locales puedan intercambiar conocimientos, experiencias y buenas prácticas, además de gestionar fondos comunitarios y llevar a cabo iniciativas de distinta naturaleza junto a otros gobiernos locales y regionales de otros Estados miembros o incluso de terceros Estados. Esta proyección más allá de las fronteras nacionales se encontraba anteriormente condicionada por las previsiones de los tratados internacionales, con el Reglamento de la UE se eliminaron parte de las trabas existentes, agilizando este modelo de cooperación y colaboración internacional60.

La finalidad última de esta figura es la construcción europea “desde abajo”, eliminando las fronteras territoriales tradicionales y la concepción de relaciones internacionales a niveles estatales ${ }^{61}$. A nivel nacional fue adoptado el Real Decreto 37/2008, de 18 de enero mediante el que se adoptan las medidas necesarias para la aplicación efectiva del Reglamento 1082/2006, del Parlamento Europeo y del Consejo, sobre la Agrupación Europea de Cooperación Territorial (AECT). El modelo que prevalece en la participación española en las AECTs es el autonómico; la mayoría de las Asociaciones se configuran únicamente por representantes regionales, mientras que los entes locales no tienen una presencia destacada. Una excepción significativa la constituye la AECT Duero-Douro, integrada por 107 municipios transfronterizos de las provincias de Zamora y Salamanca, 7 Cámaras Municipales, 69 freguesías transfronterizas portuguesas, dos asociaciones de municipios, un organismo autónomo y dos entidades académicas: la Universidad de Salamanca y el Instituto Politécnico de Bragança ${ }^{62}$.

56 Este texto fue publicado en el BOE núm. 248, de 16 de octubre de 1990 y entró en vigor para España el 25 de noviembre de 1990. Sobre esta disposición, MARTíNEZ PÉREZ, E., “El derecho de las entidades locales españolas a participar en los organismos de cooperación transfronteriza”, Anuario Aragonés del Gobierno Local 2009, 2010, pp. 235-236.

57 Creadas respectivamente en Burdeos con fecha de 15 de abril de 1983, y en Oporto, con fecha de 31 de octubre de 1991.

58 “Cumbre sobre cooperación territorial europea: Las AECT y la cooperación transfronteriza”, celebrada en Cáceres, los días 2 y 3 de mayo de 2010. El objetivo de este encuentro fue potenciar mediante el debate y el intercambio de experiencias, el desarrollo de las Agrupaciones Europeas de Cooperación Territorial y estrechar relaciones entre los distintos territorios europeos para impulsar su desarrollo económico y social.

59 Reglamento 1082/2006 del Parlamento Europeo y del Consejo, de 5 de julio de 2006, sobre la Agrupación Europea de Cooperación Territorial (AECT), DOUE L 210, de 31 de julio de 2006, arts. 1 y 3. Sobre esta figura, Fernández de Casadevante Romaní, C. y Embid Irujo, A., Las Agrupaciones europeas de cooperación territorial, Ed. Iustel, Madrid, 2008; Sanz Rubiales, I., “La Agrupación Europea de Cooperación Territorial (AECT): ¿Una nueva Administración Pública de Derecho comunitario? Algunos problemas”, Revista de Derecho Comunitario Europeo, núm. 31, 2008, pp. 673-710; Canals i Ametller, D. (coord.), Entidades locales y fronteras: instrumentos jurídicos de cooperación transfronteriza, Ed. Fundació Carles Pi i Sunyer d’Estudis Autonòmics i Locals, 2008; Martínez Pérez, E., “Las agrupaciones europeas de cooperación territorial (Unión Europea) frente a las agrupaciones eurorregionales de cooperación (Consejo de Europa): ¿Competencia o complementariedad?”, Revista de Estudios Europeos, núm. 56, 2010 (Ejemplar dedicado a: El estado de la cooperación transfronteriza hispano-portuguesa en 2010), pp. 109-126.

60 Janer Torrens, J., "La participación de los entes regionales y locales españoles en las agrupaciones europeas de cooperación territorial”, Revista de Derecho Comunitario Europeo, núm. 35, 2010, pp. 117-142; Beltrán García, S., "Qué esperar de la figura de la Agrupación Europea de Cooperación Territorial (AECT) en relación a los organismos de cooperación creados por las Comunidades Autónomas”, Revista General de Derecho Europeo, núm. 17, 2007, pp. 1-32; Pueyo Losa, J., “La cooperación transfronteriza desde la práctica de la eurorregión Galicia-norte de Portugal”, Revista de Estudios Europeos, núm. 56, 2010 (Ejemplar dedicado a: El estado de la cooperación transfronteriza hispano-portuguesa en 2010), pp. 33-49.

61 El Comité de las Regiones en su Dictamen sobre el tema "Gobernanza y asociación a nivel nacional y regional, y base para los proyectos en el ámbito de la política regional" (DOUE, C 325, de 19 de diciembre de 2008), considera que "debe tenerse en cuenta, al tiempo que debe ser impulsado, el papel que desempeñan las Agrupaciones Europeas de Cooperación Territorial en el ámbito de la gobernanza de la política regional. Estas nuevas figuras, además de un instrumento de gestión de los fondos comunitarios, son, sobretodo, una herramienta de participación horizontal al servicio de la sociedad civil de las regiones vecinas".

62 Los Estatutos y el Convenio de la AECT Duero -Douro fueron publicados el 7 de marzo de 2009 en el Diário da República de Portugal y el 21 de abril de 2009 en el Boletín Oficial del Estado español y refrendados en el Diario Oficial de la Unión Europea el 16 de junio de 2009 . A la 
En 2011 la Comisión presentó su informe sobre la aplicación del Reglamento 1082/2006, y a la vista de las conclusiones extraídas elaboró una propuesta de modificación del texto, en la que se apostaba por la continuidad de las agrupaciones si bien se instaba la incorporación de algunas novedades. Entre las propuestas de reforma se encuentran iniciativas para simplificar y aclarar algunos ámbitos del texto original, garantizar una mayor visibilidad de las AECT y favorecer su participación en cualquier ámbito de la cooperación territorial, a la vez que permitir que las autoridades y las regiones de terceros países participen como miembros ${ }^{63}$.

Las AECTs constituyen una vía más que adecuada para que los entes locales creen una red solvente de cooperación territorial. No obstante, este modelo parece que aún se limita en gran medida a las entidades locales fronterizas que, además de una importante tradición en la elaboración de agrupaciones de distinta naturaleza, se encuentran más receptivas a la creación de este tipo de estructuras territoriales ${ }^{64}$. El desafío es lograr la implantación a gran escala de este modelo, favoreciendo de esta forma la mayor implicación de las entidades locales en la gestión de los proyectos comunitarios, que en gran medida siguen recayendo en las Comunidades Autónomas y en la Administración General del Estado. En este sentido corresponde al resto de las Administraciones implicadas realizar una labor de fomento para la creación de estas redes, impulsando a los entes locales a superar sus límites tradicionales.

\section{CONSIDERACIONES FINALES}

1.Los principios de gobernanza basados en la participación ciudadana exigen inexorablemente la colaboración de los gobiernos locales. La creación de redes pasa por el ámbito local como estructura básica e inicial de cualquier tipo de iniciativa de estas características. Por tanto, los modelos de gobierno tradicionales basados en una estructura jerárquica vertical en la que la Administración General del Estado ocupaba la cúspide del esquema nacional, se transforman hacia un modelo horizontal en el que no existen vértices, tan sólo estratos de gobierno que se comunican y que dependen unos de otros.

2. Existen instrumentos para lograr la proyección de los entes locales, a nivel nacional e internacional. La cuestión que cabe plantearse tras el estudio realizado es si los gobiernos locales se encuentran sensibilizados hacia este fenómeno de cooperación y colaboración. En ocasiones parece que resultan más viables las relaciones entre entes locales de distintos Estados, que se encuentran a miles de kilómetros, que las relaciones de vecindad propiamente dichas. Potenciar las asociaciones intermunicipales y aprovechar el potencial de las sinergias que se creen en estos entornos constituyen la esencia del modelo local; esta es la única vía para que el impacto de los entes locales sobre un territorio sea efectiva y, por tanto, para la consecución de los objetivos de cohesión económica, social y territorial.

3. El componente internacional en los entornos locales goza de una doble perspectiva: por un lado nos encontramos con unas sociedades que en pocos años han sufrido un cambio radical en su composición, consecuencia lógica de los movimientos migratorios; y por otro, la acción exterior de los gobiernos locales se ha convertido en una realidad que ha superado su etapa inicial y se encuentra perfectamente asentada dentro de las líneas políticas de los entes locales. Las denominadas sociedades multiculturales constituyen un desafío para un modelo de gobierno que ha evolucionado en torno a sociedades homogéneas en las que las singularidades eran obviadas.

4. La diversidad a la que se enfrentan los entes locales va más allá de las culturales, religiosas o lingüísticas, también comprenden las necesidades de colectivos como los mayores, los jóvenes o los discapacitados que hasta ahora no tenían presencia alguna a nivel institucional. Este panorama plural obliga a plantearse si los gobiernos locales disponen de los medios suficientes para responder a estas demandas de la ciudadanía. Reforzar la capacidad teórica de actuación de los gobiernos locales y establecer nuevos desafíos en estos niveles exige dotarlos de los instrumentos necesarios para que puedan cumplir con estas expectativas. La respuesta se encuentra en la participación de la administración local en la adopción de decisiones y en la elaboración de las políticas públicas; superando la fase de administración residual, controlada y limitada por el resto de las Administraciones. Se refuerza de esta forma la iniciativa local, con lo que se acercan las políticas públicas al ciudadano, principio que ya se encuentra reconocido en las reformas estatutarias de los últimos años.

AECT Duero-Douro pertenecen 188 entidades públicas, todas ellas situadas en la NUTS III: Alto Trás-os-Montes, Douro, Beira Interior Norte y las Provincias de Salamanca y Zamora. Abarca una superficie de 8.910,27 Km2, la extensión de los kilómetros de frontera es de 356,19 y comprende una población de 73.328 habitantes portugueses y 46.815 españoles, lo que conforma un total de 120.143 habitantes. Sitio web oficial de la AECT Duero-Douro: http:// www.duero-douro.com/

63 Propuesta de Reglamento del Parlamento Europeo y del Consejo por el que se modifica el Reglamento $1082 / 2006$ del Parlamento Europeo y del Consejo, de 5 de julio de 2006, sobre la Agrupación Europea de Cooperación Territorial (AECT) en lo que se refiere a la clarificación, la simplificación y la mejora de la creación y la puesta en práctica de dichas agrupaciones, COM (2011) 610 final, Bruselas, 6 de octubre de 2011.

64 Martínez Pérez, E., op. cit., p. 258. 
5. Las situaciones de crisis económica y la pérdida de autonomía local han sido dos realidades paralelas. Los recursos destinados a la administración local no han sido considerados una prioridad en los presupuestos de la Administración Pública, ya que las funciones asumidas por los Entes locales tampoco eran clasificadas como determinantes; a pesar de incidir directamente en el bienestar del ciudadano no ocupaban una posición prevalente. Los cambios propuestos y el descubrimiento de la relevancia de la Administración local exigen alterar estas premisas; surge una nueva cuestión, ¿estarán dispuestas la Administración General del Estado y las Comunidades Autónomas, a compartir su papel protagonista con las Administraciones Locales? Al plantearnos esta duda completamos la referencia a la participación ciudadana con la indispensable participación administrativa para lograr la implantación de la gobernanza multinivel.

6. Cabría incidir en la idea de una triple renovación que afecta al ciudadano, a los entes locales y a la Administración en su conjunto. El ciudadano como origen y fin de las políticas públicas y como actor en las iniciativas adoptadas desde los poderes públicos; los entes locales replanteando su estructura interna para hacer frente a la nueva realidad social y administrativa, y para estar a la altura de las expectativas creadas; y la Administración en su conjunto, en concreto la Administración General del Estado y las Administraciones autonómicas, preparadas para respaldar la renovación local y aceptar a los gobiernos locales como sujetos participantes en la toma de decisiones.

7. La novedad por la que abogamos en este estudio es la instauración real de un nuevo modelo de gobierno; lo local como elemento vertebrador de la participación ciudadana. En este sentido, si bien desde los textos estatutarios y las disposiciones analizadas este planteamiento parece asentado desde la década pasada, la situación actual ha demostrado que aún no puede ser considerado como una realidad asumida por parte de todas las Administraciones implicadas. La fortaleza de los entes locales reside, en gran medida, en la creación de redes, ya sea a través de las agrupaciones a nivel interno o gracias a la proyección internacional; en este sentido, la superación de los límites territoriales tradicionales es un impulso para la proyección de lo local y de sus virtualidades. En el contexto actual de cambios, cuando se impone una renovación en los planteamientos tradicionales de las Administraciones públicas; nos encontramos ante un punto de inflexión en el que el desarrollo de los nuevos modelos de gobierno han de implantarse, porque es la oportunidad para probar su verdadera eficacia y su fortaleza ante las presiones que sufre el sector público.

\section{BIBLIOGRAFÍA}

Badia i Dalmases, F., “Los Gobiernos locales en la acción exterior. Una visión desde Cataluña”, Documentos CIDOB, núm. 5, septiembre de 2009.

Beltrán García, S., “Qué esperar de la figura de la Agrupación Europea de Cooperación Territorial (AECT) en relación a los organismos de cooperación creados por las Comunidades Autónomas”, Revista General de Derecho Europeo, núm. 17, 2007.

Blanco Velasco, M., "Gobernabilidad y participación ciudadana. Sociedad civil y gobierno panista”, Gobernanza y gobernabilidad democráticas en México, Programa MOST, Documentos de debate, núm. 60, 2002.

Bradley, J., "Evaluating the impact of European Unión Cohesión policy in less-developed countries and regions”, Regional Studies, 40, 2006.

Bórzel, T., "European Governance: Negotiation and Competition in the Shadow of Hierarchy", JCMS: Journal ofCommoon Market Studies, vol. 48, núm. 2, marzo 2010.

Cálame, P., La démocratie en miettes. Pour une révolution de la gouvernance, Descartes \& Cié, París, 2003.

Canals i Ametller, D. (coord.), Entidades locales y fronteras: instrumentos jurídicos de cooperación transfronteriza, Ed. Fundado Caries Pi i Sunyer d’Estudis Autonómics i Locáis, 2008.

Castel Gayan, S., “La participación ciudadana en el ámbito local: experiencias”, Revista de Estudios de la Administración Local y Autonómica, núm. 312, 2010.

Castel Gayan, S., “Descentralización política, participación ciudadana y renovación jurídica: ¿Hacia una democracia participativa?", Revista catalana de dretpúblic, núm. 43, 2011.

Cerrillo i Martínez, A., “La ayuda al desarrollo y los Entes Locales”, Anuario del Gobierno Local. Configuración Jurídica de la Autonomía Local. Municipio y transformaciones sociales. Urbanismo e Inmigración, Instituto de Derecho Público, Barcelona, 2001.

Clark, G., "Ciudades abiertas, gobernanza y cohesión” en Pascual Esteve, J. y Pascual Guiteras, J. (coords.), Cohesión Social y Gobernanza democrática: Para unas regiones y ciudades más inclusivas, Junta de Andalucía, Consejería de Gobernación, 2009. 
Colino, C, "Democracia, participación ciudadana y problemas de la gestión de los gobiernos locales en Europa: la equidad, la eficiencia y la capacidad", VII Congreso Internacional del CLAD sobre la Reforma del Estado y de la Administración Pública, Lisboa, 8 -11 de octubre de 2002, Comisión Europea, Política de cohesión 2014-2020. Inversión en el crecimiento y el empleo, Oficina de Publicaciones de la Unión Europea, Luxemburgo, 2011.

Comisión Europea, European Territorial Cooperation. Building bridges between people, Oficina de Publicaciones de la Unión Europea, Luxemburgo, 2011.

Comunidades Europeas, Fondo Social Europeo. Invertir en las personas, Oficina de Publicaciones Oficiales de las Comunidades Europeas, Luxemburgo, 2007.

Eckersley, R., The Green State. Rethinking Democracy and Sovereignty, The MIT Press, Cambridge Massachusetts, 2004.

Erlxon, F., “The Europe 2020 strategy: time for Europe to think again”, European View, vol. 9, 1, junio de 2010.

Fabeiro Mosquera, A., "La Carta municipal de Barcelona: Notas sobre sus especialidades", RDUNED: Revista de Derecho de la UNED, núm. 1, 2006.

Fernández de Casadevante Romaní, C. y Embid Irujo, A., Las Agrupaciones europeas de cooperación territorial, Ed. lustel, Madrid, 2008.

Ferreira, A.X., "La cooperación municipal en España: los entes supramunicipales en el ordenamiento jurídico español”, Urban Public Economics Review, núm. 6, 2006.

Font i Llovet, T., "La Carta Municipal de Barcelona en la reforma del régimen local”, Punt de vista, núm. 7, Fundación Pi y Suyer, 2000.

Font i Llovet, T., La Carta Municipal de Barcelona. Diez estudios, Marcial Pons, 2007. García Rubio, F., “Ámbito de actuación de las comarcas", Revista General de Legislación y Jurisprudencia, núm. 1, 2008.

García-Santesmases Fernández, A., Documentación social, núm. 157, 2010.

Janer Torrens, J., "La participación de los entes regionales y locales españoles en las agrupaciones europeas de cooperación territorial”, Revista de Derecho Comunitario Europeo, núm. 35,2010.

Lannoo, K., "Europe 2020 and the Financial System: Smaller is beautiful”, Centre for European Policies Studies. Policy Brief, núm. 211, julio 2010.

Laroca Cervigón, F. y Ferrer Matvieychuc, G., "Valencia y Barcelona ante el desarrollo sostenible. ¿Sustentabilidad o marketing ambiental?”, Agora. Revista de Ciencias Sociales, núm. 11, 2004.

Lasagabaster Herrarte, I., La carta europea de la autonomía local, lustel, Madrid, 2007,

Male, J., Especificidades de la cooperación descentralizada pública: actores, contenidos y modelos, Observatorio de la Cooperación Descentralizada Unión Europea - América Latina, Montevideo, Marzo, 2006.

Mariscal, N., Más allá de Lisboa: Horizontes europeos, Editorial Tecnos, 2010.

Marsal, M., "Los poderes locales ante el Tratado de Niza y la perspectiva de ampliación de la Unión Europea”, Anuario del Gobierno Local. Configuración Jurídica de la Autonomía Local. Municipio y transformaciones sociales. Urbanismo e Inmigración, Instituto de Derecho Público, Barcelona, 2001.

Marsal, M., "Recomendación del Congreso de los Poderes Locales y Regionales de Europea sobre la democracia local y regional en España", Anuario del Gobierno Local. La Ley de Modernización del Gobierno Local. Cooperación intermunicipal, Instituto de Derecho Público, Barcelona, 2003.

Martínez Pérez, E., "El derecho de las entidades locales españolas a participar en los organismos de cooperación transfronteriza”, Anuario Aragonés del Gobierno Local 2009, 2010.

Martínez Pérez, E., "Las agrupaciones europeas de cooperación territorial (Unión Europea) frente a las agrupaciones eurorregionales de cooperación (Consejo de Europa): ¿Competencia o complementariedad?”, Revista de Estudios Europeos, núm. 56, 2010 (Ejemplar dedicado a: El estado de la cooperación transfronteriza hispano-portuguesa en 2010).

Marx, V., Tesis Doctoral: Las ciudades como actores políticos en las relaciones internacionales, Barcelona, julio de 2008.

Medina Guerrero, M., La promoción de la rendición de cuentas y la participación ciudadana en los procesos de descentralización, FÜAPP-Instituto Universitario de Desarrollo y Cooperación, Madrid, 2006.

Mol, A., Globalization and Environmetal Reform, The MIT Press, Cambridge Massachusetts, 2004. 
Morata, F., “Gobernanza multinivel en la Unión Europea”, VII Congreso Internacional del Centro Latinoamericano de Administración para el Desarrollo sobre la Reforma del Estado y de la Administración Pública, Lisboa (Portugal), 8-11 de octubre de 2002.

Morata, F, Gobernanza multinivel en la Unión Europea, Tirant lo Blanch, 2004.

Natera Peral, A., “La gestión de redes de gobernanza: un reto para el Estado y la democracia”, Revista Administrare si managementpublic, núm. 3, 2004.

Navarro Gómez, C, “Gobernanza en el ámbito local”, VII Congreso Internacional del Centro Latinoamericano de Administración para el Desarrollo sobre la Reforma del Estado y de la Administración Pública, Lisboa (Portugal), 8-11 de octubre de 2002. Ordóñez Solís, D., “Los entes regionales y locales en la Unión Europea: La experiencia española”, Actualidad Administrativa, núm. 44, 1999.

Pons Ráfols, X., “La acción exterior de la Generalitat en la Sentencia del Tribunal Constitucional sobre el Estatuto de Autonomía de Cataluña”, Revista catalana de dret públic, Especial Sentencia sobre el Estatuto, 2010.

Pueyo Losa, J., “La cooperación transfronteriza desde la práctica de la eurorregión Galicia-norte de Portugal”, Revista de Estudios Europeos, núm. 56, 2010 (Ejemplar dedicado a: El estado de la cooperación transfronteriza hispano-portuguesa en 2010).

Romero, M., “Una aproximación contextual y conceptual a la Cooperación Descentralizada”, en Tejiendo Lazos entre Territorios. La Cooperación Descentralizada Local UE-América Latina, Diputado de Barcelona, Municipalidad de Valparaíso, 2004.

Rubiera Morollón, F., “Nuevas orientaciones estratégicas de la política de cohesión de la Unión Europea: una revisión de posibles acciones adaptadas al nuevo enfoque”, Revista de Estudios Regionales, núm. 81, 2008.

Sánchez Blanco, en “Modernización del gobierno local y gobernanza europea”, Revista Jurídica de Castilla y León, núm. 1, septiembre de 2003.

Sánchez Blanco, A., Organización Intermunicipal, lustel, Madrid, 2006.

Sánchez Blanco, A., "Urbanismo, prácticas municipales y evaluación institucional del Estado Español: la Resolución del Parlamento Europeo sobre el impacto de la urbanización extensiva en España en los derechos individuales de ios ciudadanos europeos, el medio ambiente y la aplicación del Derecho comunitario", Revista de Estudios de la Administración Local y Autonómica, núm. 310, 2009.

Sandri, G., "Le politiche strutturali comunitarie e le regioni: modelli di partecipazione subnazionale al decisionmaking europeo”, XXI Congresso della Societá Italiana di Scienza Política, Universitá di Catania, Facoltá di Scienze Politiche, 20-22 Septiembre, 2007.

Sánchez Morón, M., "Reflexiones sobre la participación del ciudadano en las funciones administrativas en el sistema constitucional español”, Revista catalana de dret públic, núm. 37, 2008.

Sanz Rubiales, I., “La Agrupación Europea de Cooperación Territorial (AECT): ¿Una nueva Administración Pública de Derecho comunitario? Algunos problemas”, Revista de Derecho Comunitario Europeo, núm. 31, 2008.

Scarciglia, R., "La forma de gobierno local y la circulación de los modelos en la Europa centro-oriental”, Anuario del Gobierno Local. Configuración Jurídica de la Autonomía Local. Municipio y transformaciones sociales. Urbanismo e Inmigración, Instituto de Derecho Público, Barcelona, 2001.

Sobrino Heredia, J., "El principio de subsidiariedad y la participación de los entes locales y regionales en la Unión Europea”, Noticias de la Unión Europea, núm. 145, 1997.

Tejada Gallegos, “Marco jurídico y financiero para un modelo territorial cooperativo”, en AA.W., El municipalismo en un Estado cooperativo, Federación Española de Municipios y Provincias, 2009.

Torres Cobas, F., “Perversiones y novedades de la cooperación municipal”, Anuario del Gobierno Local. La Ley de Modernización del Gobierno Local. Cooperación intermunicipal, Instituto de Derecho Público, Barcelona, 2003.

Tur Ausina, R., “Participación ciudadana. Oportunidad, necesidad y esencia de su regulación legal”, Revista Deliberación, Departamento de Presidencia del Gobierno de Aragón, núm. 1, 2010.

Vara Arribas, G., “Gobemanza multínivel en la Unión Europea y las regiones, con o sin una Constitución”, Revista Aragonesa de Administración Pública, núm. 29, 2006. 